\title{
Characterization of atmospheric aerosol in the US Southeast from ground- and space-based measurements over the past decade
}

\author{
E. J. Alston ${ }^{1,2}$, I. N. Sokolik ${ }^{2}$, and O. V. Kalashnikova ${ }^{3}$ \\ ${ }^{1}$ NASA Langley Research Center, Hampton, VA, USA \\ ${ }^{2}$ Georgia Institute of Technology, School of Earth and Atmospheric Sciences, Atlanta, GA, USA \\ ${ }^{3}$ Jet Propulsion Laboratory, California Institute of Technology, Pasadena, CA, USA
}

Correspondence to: E. J. Alston (erica.j.alston@nasa.gov)

Received: 11 October 2011 - Published in Atmos. Meas. Tech. Discuss.: 16 December 2011

Revised: 4 June 2012 - Accepted: 18 June 2012 - Published: 18 July 2012

\begin{abstract}
This study examines how aerosols measured from the ground and space over the US Southeast change temporally over a regional scale during the past decade. $\mathrm{PM}_{2.5}$ (particulate matter with aerodynamic diameter $>2.5 \mathrm{mi}-$ crometers) data consist of two datasets that represent the measurements that are used for regulatory purposes by the US EPA (Environmental Protection Agency) and continuous measurements used for quickly disseminating air quality information. AOD (aerosol optical depth) data come from three NASA sensors: the MODIS sensors onboard Terra and Aqua satellites and the MISR sensor onboard the Terra satellite. We analyze all available data over the state of Georgia from 2000-2009 of both types of aerosol data. The analysis reveals that during the summer the large metropolitan area of Atlanta has average $\mathrm{PM}_{2.5}$ concentrations that are $50 \%$ more than the remainder of the state. Strong seasonality is detected in both the AOD and $\mathrm{PM}_{2.5}$ datasets, as evidenced by a threefold increase of AOD from mean winter values to mean summer values, and the increase in $\mathrm{PM}_{2.5}$ concentrations is almost twofold over the same period. Additionally, there is agreement between MODIS and MISR onboard the Terra satellite during the spring and summer, having correlation coefficients of 0.64 and 0.71 , respectively. Monthly anomalies were used to determine the presence of a trend in all considered aerosol datasets. We found negative linear trends for both the monthly AOD anomalies from MODIS onboard Terra and the $\mathrm{PM}_{2.5}$ datasets, which are statistically significant. Decreasing trends were also found for MISR onboard Terra and MODIS onboard Aqua, but those trends were not statistically significant. The observed decrease in AOD and $\mathrm{PM}_{2.5}$ concentrations may be indicative of the brightening over the study region during the past decade.
\end{abstract}

\section{Introduction}

Over the past fifty or so years, global ground-based measurements of solar radiation reaching the surface have shown first a decrease (i.e., dimming) and in the last fifteen years have shown an increase (i.e., brightening) (Alpert et al., 2005; Gilgen et al., 2009; Wild et al., 2009). The solar dimming relates to increases in aerosol concentration that prevent incoming solar radiation from reaching the surface. During the 1980s, many industrialized countries enacted policies for controlling emissions of aerosols and their precursors. In the 1990s, a shift from dimming to brightening was reported at some locations (Streets et al., 2009). It is hypothesized that the magnitude of global warming has been masked due to solar dimming (Schwartz et al., 2010; Wild et al., 2009), thus linking this phenomenon to current climate.

Dutton et al. (2006) analyzed twenty-seven years of NOAA/GMD surface solar irradiance data from five remote sites (Barrow, AK USA; Boulder, CO USA; Mauna Loa, HA USA; American Samoa; and the South Pole) and concluded that while the sites span a large geographic area, the behaviour of surface solar irradiance was similar (decreasing then increasing with time) across the sites. Wild et al. (2009) provide updates of surface radiation measurements through 2005 and present evidence that brightening across large areas is ongoing and that anthropogenic contributions are an important factor in this phenomenon. Streets et al. (2009) use model-predicted aerosol optical depth to determine the regional nature of solar dimming/brightening. Their results indicate that the US, Europe and Russia have decreasing AOD (aerosol optical depth) values over a twenty-five year 
(1980-2005) period, and these regions also have a strong linear relationship between AOD and surface radiation.

The regionality associated with this solar dimming/brightening is more nuanced when observed from a smaller regional perspective, e.g., regions of the US. For example, some studies found that solar dimming/brightening is likely dominated by emissions from large urban areas (Alpert and Kischa, 2008; Alpert et al., 2005). Recent work by Wild et al. (2009) further substantiates this point by investigation of trends of solar dimming/brightening at multiple locations. The locations from the US all show a similar behaviour, but each site's trend slope is different, owing to the influence of differing aerosol mixtures and loading associated with each site's respective region. Long et al. (2009) investigated brightening of downwelling shortwave radiation at multiple US locations and found that collectively the brightening is significant, but that the varying degrees of brightening amongst the different sites suggested that research into dimming/brightening should address local to regional scales. Ultimately, understanding of dimming/brightening variations requires knowledge of spatiotemporal changes in aerosols on a regional basis. The focus of the present study is on a regional aerosol signal in the Southeast US.

This region is of interest because of the distinct aerosol mixtures associated with this geographic region that has been studied from the ground, yet little research has been done incorporating satellite data into longer term studies. There have been, for instance, large scale groundbased measurement studies in the region consisting of a US Environmental Protection Agency (EPA) Supersite Study (Solomon et al., 2003b), and ongoing work through the Southeastern Aerosol Research and Characterization Study (SEARCH) (http://www.atmospheric-research.com/studies/ SEARCH/index.html). According to the EPA Our Nation's Air publication (http://www.epa.gov/airtrends/2010/ index.html), $\mathrm{PM}_{2.5}$ (particulate matter with an aerodynamic diameter less than 2.5 micrometers) concentrations nationwide have decreased by $19 \%$ since 2000 , with the Southeastern US showing a decrease in annual $\mathrm{PM}_{2.5}$ concentrations. This region is distinctly characterized by aerosols composed of primarily sulfates and organics (Edgerton et al., 2005; Weber et al., 2007). Measurements and modeling studies have shown that organic aerosol formed by secondary processes is biogenic in origin and fairly homogeneous over the region (Lee et al., 2010). Goldstein et al. (2009) hypothesize that the haze commonly seen in the region during the warmer summer months is formed from secondary organic aerosols (SOA) formed from biogenic volatile organic compounds (BVOC) that tend to cause a cooling radiative effect at the top of the atmosphere (TOA) and that these BVOC SOA aerosols form a layer aloft in the atmosphere with a dominant contribution to AOD during the summer.

Ground-based measurements can provide high temporal resolution data over an extended period of time, yet these measurements are generally limited in their geographic coverage. A majority of ground-based measurement sites are mostly in areas with high population densities. Additionally, ground-based measurements are at best representative of aerosols in the lower atmosphere, mainly in the planetary boundary layer (PBL); as such, these measurements miss aerosols aloft, especially transport events. While satellites have an advantage in that they can view regions as a whole, enabling a better understanding of the regional aerosol dynamics, the satellites are limited temporally with only one or two sunlit overpasses of a region per day. The National Aeronautics and Space Administration (NASA) has launched a couple of satellites (Terra and Aqua) that have near global coverage daily with direct application to aerosols. The MODIS and MISR sensors onboard Terra have been operational for over ten years. MODIS onboard Aqua was launched in 2002. Each sensor provides a continuous time series of the aerosol optical depth that can be directly related to the dimming/brightening phenomena (Hinkelman et al., 2009; Mishchenko et al., 2007). However, retrievals of AOD (a unitless measure of the amount of light attenuation over a set distance over the entire atmospheric column) are associated with a number of problems, especially over land such as deserts or urban environments. Liu and Mishchenko (2008) found that MODIS and MISR retrievals can disagree on a regional basis; yet, Kahn et al. $(2009,2011)$ attempted to disprove those findings in concluding that MISR and MODIS retrievals are in agreement and provided details on the causes of the discrepancies between the two.

There have been studies that directly relate satellite AOD to $\mathrm{PM}_{2.5}$ concentrations in the US and the Southeastern US specifically for the purposes of predicting air quality (EngelCox et al., 2004; Gupta and Christopher, 2008, 2009; Zhang et al., 2009). A recent review about the state of the field is presented in Hoff and Christopher (2009). In our earlier work, we also examined the use of satellite AOD products for air quality analysis, which lead to the development of a statistical technique for predicting air quality index values in the Atlanta metropolitan area (Alston et al., 2011). Although the above studies were mainly focused on predicting $\mathrm{PM}_{2.5}$ from AOD for air quality applications, they did reveal some important similarities and differences in the behaviour of $\mathrm{PM}_{2.5}$ measured near the ground and AOD retrieved from space-borne instruments. When the behaviour of aerosols is examined over a longer time period, there is the potential to provide useful insight into the variability of aerosols in the context of the solar dimming/brightening phenomena and climate change in general. Given the regional nature of aerosols and inherent difficulties and limitations in both satellite and ground based observations, it is important to utilize multiple sensors in aerosol analysis in order to develop as accurate understanding of aerosol behaviour as possible especially at longer time scales.

This provided a motivation behind the present study. Our goal is to characterize aerosols in the US Southeast through 
analysis of ground- and space-based measurements from 2000-2009 with an emphasis on seasonal and inter-annual aerosol variations, and to understand these variations in the context of the radiative impact of aerosols on climate. The specific objectives are to examine the temporal changes of ground based $\mathrm{PM}_{2.5}$ and AODs from MODIS and MISR over the past ten years, determine common features and differences between these data records, determine if there is a discernible trend, and if a trend is present, what are the implications for the region in the context of the dimming/brightening phenomena. We analyzed ten years of AOD from MODIS and MISR onboard Terra and eight years for MODIS onboard Aqua over a $5^{\circ} \times 5^{\circ}$ box that encompasses the state of Georgia. This analysis also uses ten years of filter-based $\mathrm{PM}_{2.5}$ data provided by the EPA, and all available data from Georgia-run continuous $\mathrm{PM}_{2.5}$ monitors. This paper is organized as follows. Section 2 introduces the data and methods used in this study. Section 3 presents the results, and Sect. 4 concludes with a summary and discussion.

\section{Data and methodology}

\subsection{Ground-based $\mathbf{P M}_{2.5}$ data}

We use surface $\mathrm{PM}_{2.5}$ dry mass measurements from two different networks: the ten-year record from the national network of filter-based $\mathrm{PM}_{2.5}$ monitors courtesy of the EPA, and a seven-year record of continuous $\mathrm{PM}_{2.5}$ measurements provided by the Georgia Dept. of Natural Resources. The location of the sites is shown in Fig. 1. The network operated by the Georgia Dept. of Natural Resources (http://www.air.dnr. state.ga.us/amp/) performs continuous hourly measurements using TEOMs (Tapered Element Oscillating Microbalance). Across Georgia, there are eighteen network sites located primarily within or near a city. For our study we use twelve sites. Seven of those sites are within the large metropolitan area of Atlanta and the remaining sites are smaller sized cities and towns. Most of the stations have seven years of data; therefore, sites without at least five years of data were excluded from this analysis. Henceforth, this dataset will be annotated as $\mathrm{PM}_{2.5, \mathrm{TEOM}}$. The time coverage of this dataset is from 2003-2009.

The second data set is provided by the EPA Air Quality Monitoring System (http://www.epa.gov/airexplorer/index. $\mathrm{htm})$. The data from this network are used for air quality regulatory purposes, e.g., attainment/non-attainment designations. Each monitor is filter-based according to EPAdefined reference methods described in 40 CFR Part 53 (http://www.epa.gov/ttnamti1/40cfr53.html), and they must meet high quality control measures. Due to high level of quality control, there is usually a time lag from the measurement, the analysis, and finally making the data publicly available. Each station serves a different purpose; as such there are different repeat cycles. Population exposure mon-

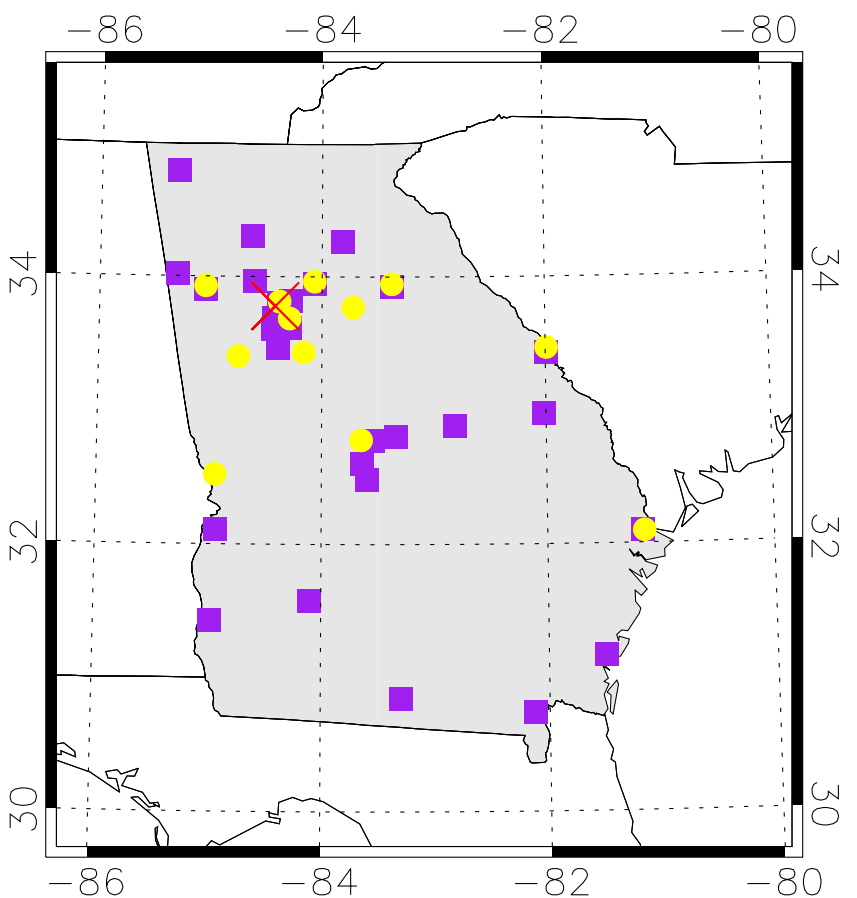

Fig. 1. Map of the US Southeast. Green box with red outline denotes study spatial domain for satellites $5^{\circ} \times 5^{\circ}$. Yellow markers represent EPA $\mathrm{PM}_{2.5}$ monitors $\left(\mathrm{PM}_{2.5}\right.$,FRM). Purple markers represent TEOM PM 2.5 monitors ( $\left.\mathrm{PM}_{2.5, \mathrm{TEOM}}\right)$.

itors have daily concentrations, while the majority of sites have a 3-day repeat cycle. Monitors that capture background conditions have a 6-day repeat cycle. We only used data on available days and no temporal interpolation was performed. Similar to our methodology for the $\mathrm{PM}_{2.5}$,TEOM dataset, we only use EPA sites within Georgia state lines; consequently we use data from 29 sites. This dataset will be annotated as $\mathrm{PM}_{2.5, \text { FRM }}$. Over half of the $\mathrm{PM}_{2.5, \mathrm{FRM}}$ stations have data that encompass 2000-2009.

To separate out Atlanta's influence from the remainder of the state, we split each $\mathrm{PM}_{2.5}$ dataset into subsets depending on the geographical location of the considered sites. Ultimately, we have three subsets for each $\mathrm{PM}_{2.5}$. We calculate a statewide mean for the All GA subset. The Atlanta subset is the mean exclusively using Atlanta sites. The last subset Outside Atlanta uses sites outside Atlanta for the calculated

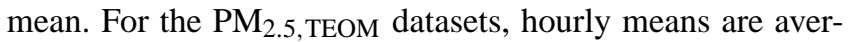
aged to create daily means. Those daily means are then used in subsequent analyses.

\subsection{MODIS data}

The MODerate Resolution Imaging Spectroradiometer (MODIS) instrument flies onboard two NASA Earth Observing System (EOS) satellites: Terra and Aqua. Both sensors have near global coverage daily. Terra flies in the descending polar orbit with an equatorial crossing time of approximately 
10:30, while Aqua flies in the ascending polar orbit with an equatorial crossing time of approximately 13:30. Generally, the satellites have overpass times over Georgia 515 min before/after (Aqua/Terra) their equatorial crossing times, though the majority of instances required multiple MODIS granules to fully cover the region.

MODIS passively measures reflected radiances from Earth across a broad wavelength spectrum. It primarily uses three channels $(0.47,0.66$, and $2.12 \mu \mathrm{m})$ to measure atmospheric aerosols over land (Levy et al., 2007). MODIS data are obtained from NASA LAADS (Level 1 and Atmosphere Archive and Distribution System). This analysis is performed with MODIS Collection 5 Level 2 MOD04 data, which have a nominal resolution of $10 \times 10 \mathrm{~km}^{2}$ at nadir. The variable of most importance to this study is Optical Depth Land and Ocean at the $550 \mathrm{~nm}$ wavelength, which incorporates only the highest quality retrievals. A global analysis over land found that greater than $66 \%$ of MODIS Collection 5 AOD compare to AERONET observed AOD values with an expected error envelope of $\pm(0.05+0.15 \%)$, with high correlations $(R$-value $=0.9)($ Levy et al., 2010) .

\subsection{MISR data}

The Multi-angle Imaging SpectroRadiometer (MISR) flies onboard of the Terra satellite together with MODIS. MISR is a multi-angle imaging instrument consisting of nine cameras with view angles of $\pm 70.5^{\circ}, \pm 60.0^{\circ}, \pm 45.6^{\circ}, \pm 26.1^{\circ}$, and $0^{\circ}$ (nadir), operating in four spectral bands centered at $446 \mathrm{~nm}$ (blue), $558 \mathrm{~nm}$ (green), $672 \mathrm{~nm}$ (red), and $867 \mathrm{~nm}$ (near infrared). In global observing mode, the spatial resolution of the red band is $275 \mathrm{~m}$ in all nine cameras; the other bands are re-sampled to $1.1 \mathrm{~km}$ resolution in all the cameras, except the nadir, which preserves the full $275 \mathrm{~m}$ resolution in all four bands. The common swath width is $\approx 400 \mathrm{~km}$ and global coverage is obtained every nine days at the Equator and more frequently at higher latitudes (Diner et al., 2002). MISR operational aerosol retrievals are performed at $17.6 \mathrm{~km}$ horizontal resolution, and particle size, shape, and single-scattering albedo are retrieved in addition to AOD (Martonchik et al., 2002, 2009). A global comparison of coincident MISR and AERONET sunphotometer data showed that overall about $70 \%$ to $75 \%$ of MISR AOD retrievals fall within 0.05 or $20 \%$ of AOD, and about $50 \%$ to $55 \%$ are within 0.03 or $10 \%$ of AOD, except at sites where dust or mixed dust and smoke are commonly found (Kahn et al., 2010). MISR data were obtained from NASA Langley ASDC (Atmospheric Science Data Center). The analysis is performed with MISR version 22 Level 2 aerosol data. The used AOD values are "best estimate AOD" at MISR green $(558 \mathrm{~nm})$ band that combines the land and ocean AOD products.

For each satellite, we create a subset based on the latitude/longitude box $30.5^{\circ} \mathrm{N}-35.5^{\circ} \mathrm{N}$ and $81^{\circ} \mathrm{W}-86^{\circ} \mathrm{W}$. All the satellite pixels contained within that latitude/longitude box are co-located and averaged together to create a regional mean AOD value on a daily basis for each satellite sensor. We require over $50 \%$ of the domain to have valid AOD retrievals each day to calculate daily averages, and days below this threshold were not included in the monthly statistics. These daily mean AOD values are used in the creation of monthly mean AOD. We also require that over 20 days to be valid for inclusion in the monthly statistics, which are used in the subsequent analyses. For spatial analysis the nominal Level 2 products are used to create maps of AOD from both Terra instruments. The daily granules are averaged on a global grid $\left(0.2^{\circ} \times 0.2^{\circ}\right.$ for MODIS and MISR). These gridded data are then averaged to create seasonal means of AOD fields for the ten-year time period covering the aforementioned latitude/longitude box.

\section{Results}

\subsection{Seasonal cycle}

Where available, we analyzed $10 \mathrm{yr}$ of $\mathrm{PM}_{2.5 \text {,TEOM, }}$

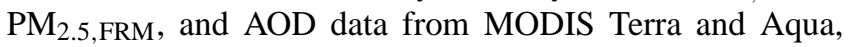
and MISR Terra to investigate the seasonal aerosol signatures over the US Southeast. Considering only spring and summer seasons in our previous study (Alston et al., 2011), we found that $\mathrm{PM}_{2.5}$ and AOD have different seasonal traits with AOD values almost doubling during the summer compared to values in the spring. Here we examine the seasonal behaviour by calculating 10 -yr (if available) averages of each month for both the satellite and $\mathrm{PM}_{2.5}$ datasets. The results are shown in Fig. 2. Analyzing a full calendar year, we determine that summer (June-August) AOD $(0.32-0.35)$ is almost tripled from wintertime (DecemberFebruary) AOD (0.08-0.1). MODIS Terra has the highest average AOD, and both MODIS sensors have higher AOD than MISR. During the summer months the difference between the MODIS AOD sensors and MISR AOD is about 0.1 , while the difference between the MODIS AOD sensors at its highest is about 0.025 . The noted $3 \times$ increase cannot be fully attributable to $\mathrm{PM}_{2.5}$ increases over the same period. In addition, the different $\mathrm{PM}_{2.5}$ datasets behave differently, with $\mathrm{PM}_{2.5}$,TEOM doubling concentrations during the summer whereas $\mathrm{PM}_{2.5, \mathrm{FRM}}$ shows only a modest increase over the same period $\left(\approx 10.0 \mu \mathrm{g} \mathrm{m}^{-3}\right.$ during the winter to $\approx 18.0 \mu \mathrm{g} \mathrm{m}^{-3}$ during the summer). The standard error (standard deviation/number of observations) of the means of both datasets show more variability during the warmer months (see Fig. 2).

Time series of monthly mean data for each year are shown in Fig. 3a. Clearly, in all years the winter months have the lowest values of AOD and $\mathrm{PM}_{2.5}$, while the summer months have the highest. Specifically, July and August have the highest AOD values with maxima over the years varying between $0.5-1.5$, and January and December having the lowest values between 0.2-0.55. MODIS Aqua has a much tighter AOD 

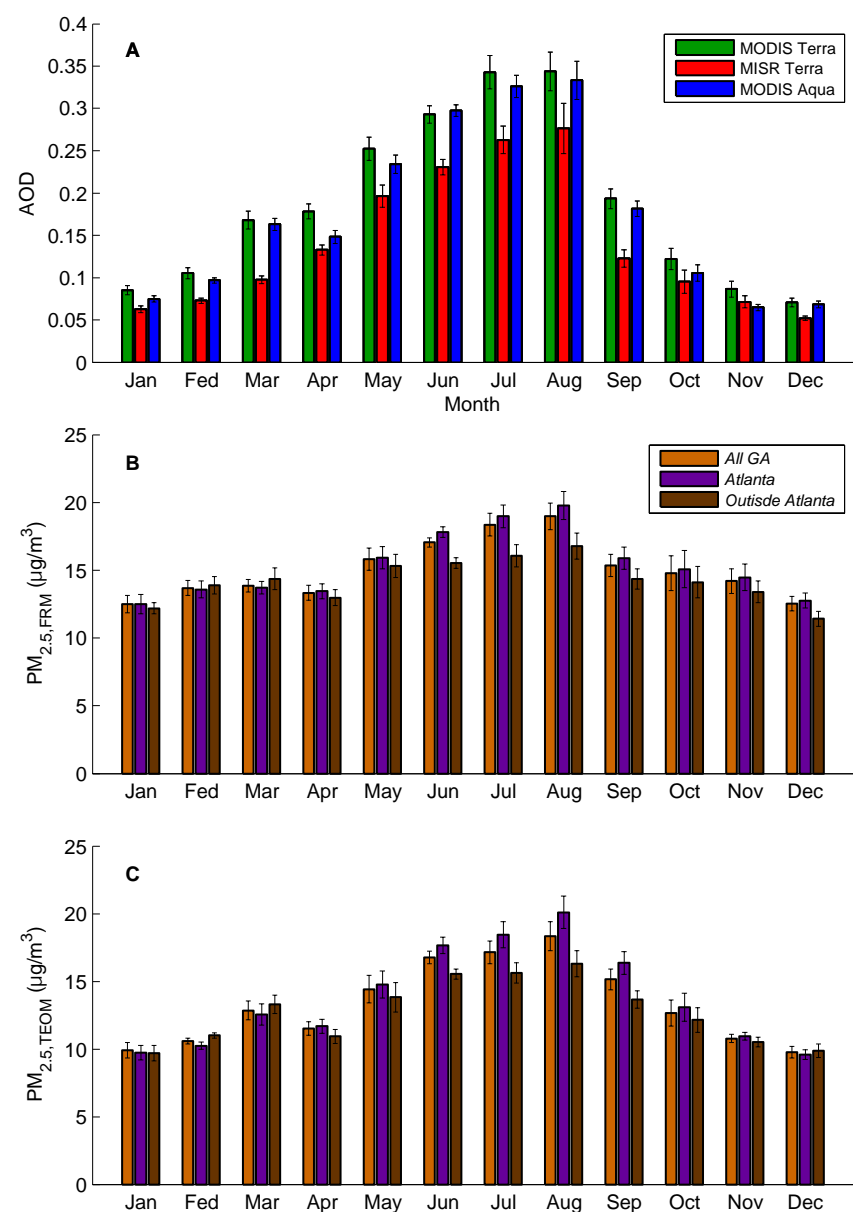

Fig. 2. (A) Bar plots of ten-year means by month for MODIS Terra AOD, MISR Terra AOD and MODIS Aqua AOD. (B) Same as (A) except for $\mathrm{PM}_{2.5, \mathrm{FRM}}$ All GA,

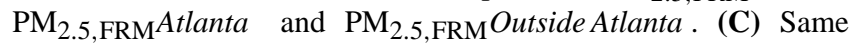
as (A) except for $\mathrm{PM}_{2.5, \mathrm{TEOM}}$ All GA, $\mathrm{PM}_{2.5, \mathrm{TEOM}}$ Atlanta and

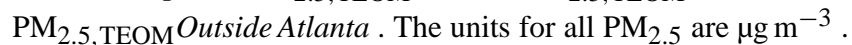
Whiskers represent \pm standard error of the mean for each respective dataset.

envelope, with wintertime AOD values between 0.05-0.08 and summertime AOD values between 0.25-0.5.

For a majority of the year, the satellite datasets show low inter-annual seasonal variability, with the highest variability occurring in the summer. The $\mathrm{PM}_{2.5}$ datasets have more inter-annual variability than the satellite datasets. Analyzing the $\mathrm{PM}_{2.5}$ datasets by different geographic regions allows us to evaluate the effect of the large urban area of Atlanta on the region as a whole. Atlanta concentrations from both $\mathrm{PM}_{2.5 \text {,TEOM }}$ and $\mathrm{PM}_{2.5 \text {,FRM }}$ exhibit more variability throughout the year when compared to stations outside the Atlanta metropolitan area (see Fig. 3b, D-I). Our results suggest that during the summer there is a complex dynamic relationship between regional background $\mathrm{PM}_{2.5}$ concentrations and anthropogenic emissions that lead to Atlanta having a $50 \%$ or
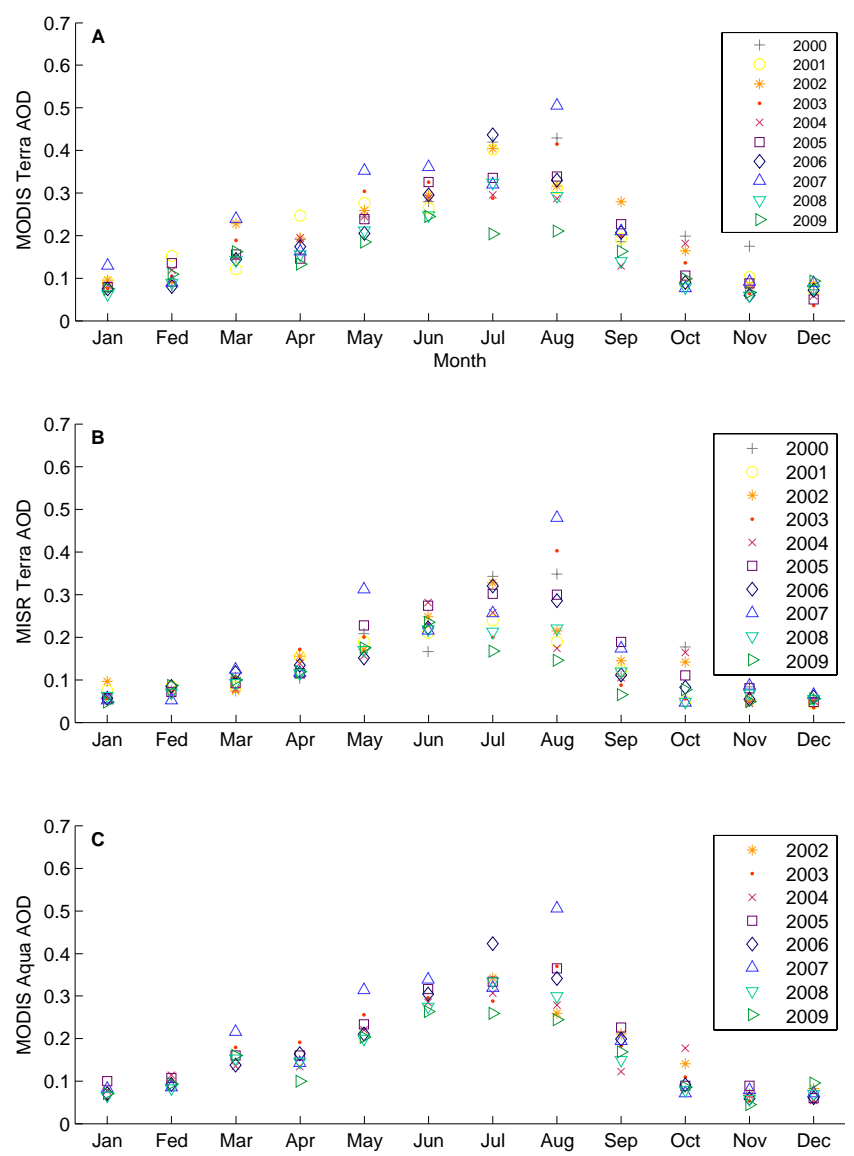

Fig. 3a. (A-C) Multi-year plots of monthly means for MODIS Terra AOD, MISR Terra AOD, and MODIS Aqua AOD.

more increase in surface concentrations that are not observed elsewhere in the state.

Compared to other years, the year 2007 has higher values in several months in all the datasets. During the early spring (March), there were numerous small scale wildfires across the Southeastern US that had long burn periods due to persistent drought across the region. The satellite and $\mathrm{PM}_{2.5 \text {,TEOM }}$ datasets capture the localized impacts of these fires, though

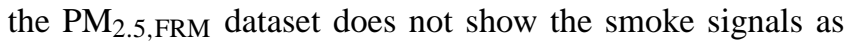
clearly. It should also be noted that these smaller scale wildfires did not cause any air quality exceedances. From late April till early June the wildfire, named the Bugaboo Scrube fire (http://en.wikipedia.org/wiki/Bugaboo_Scrub_Fire), took place in the Okefenokee National Wildlife Refuge in extreme Southeastern Georgia near the Florida border. This fire burned over 45 days and consumed over 400,000 acres, making it the largest wildfire in Southeastern US history. Smoke was transported northwest to Atlanta, thereby increasing monthly mean $\mathrm{PM}_{2.5}$ and AOD. Mostly during May 2007 $\mathrm{PM}_{2.5}$ concentrations rose to over $150 \mu \mathrm{g} \mathrm{m}^{-3}$ and AOD hovered around 1. Drought conditions were widespread not only in this region, but also in the boreal forest region of 

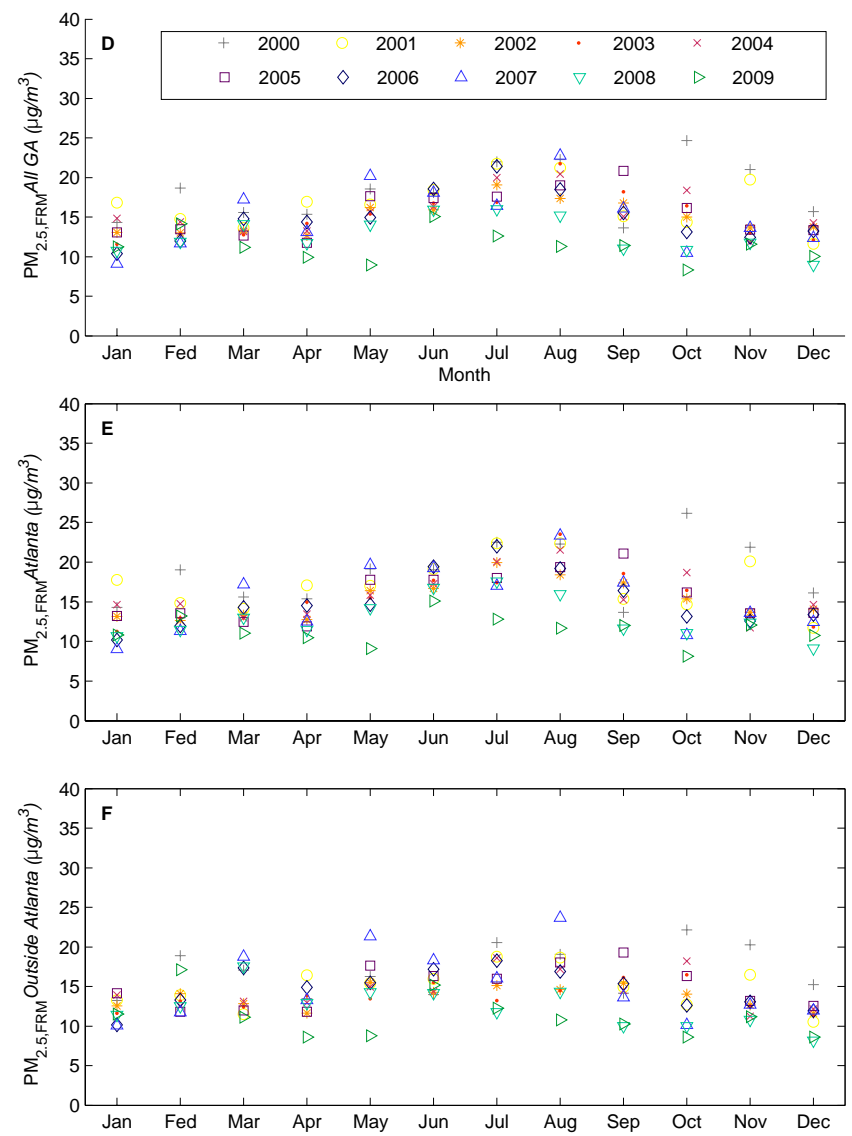

Fig. 3b. (D-F) Multi-year plots of monthly means for $\quad \mathrm{PM}_{2.5, \mathrm{FRM}}$ All $\mathrm{GA}, \quad \mathrm{PM}_{2.5, \mathrm{FRM} \text { Atlanta and }}$

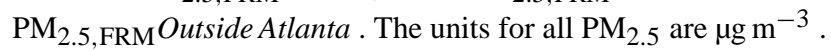

the Northwestern US (http://droughtmonitor.unl.edu/). There were numerous large scale wildfires that burned across the Western US that impacted AOD and $\mathrm{PM}_{2.5}$ observations in the study region, as seen in Fig. 3. The Smog Blog (http:// alg.umbc.edu/usaq/) provides thorough analysis of the wildfire impacts during the summer of 2007. The strongest effect of the transported smoke is seen in August 2007 where there were ten air quality exceedance days of $\mathrm{PM}_{2.5}$ concentrations and AOD values during this period of time were greater than 0.7 .

In addition to episodic smoke events, there are a number of factors that might contribute to the differences in the seasonal cycle seen in Figs. 2 and 3. One important factor is the effect of hygroscopic aerosol growth during the summer months, given much higher relative humidity in the summer. Though satellite retrieval algorithms do not directly incorporate relative humidity, the retrievals are affected (Wang and Martin, 2007). Another possibility could be due to the differences in measurement techniques used. For instance, TEOM based measurements are generally biased low with respect to the EPA $\mathrm{PM}_{2.5}$ measurements $\left(\mathrm{PM}_{2.5 \text {,FRM }}\right.$ (Carrico et al., 2003; Solomon et al., 2003a; Weber et al., 2003). Also, dif-
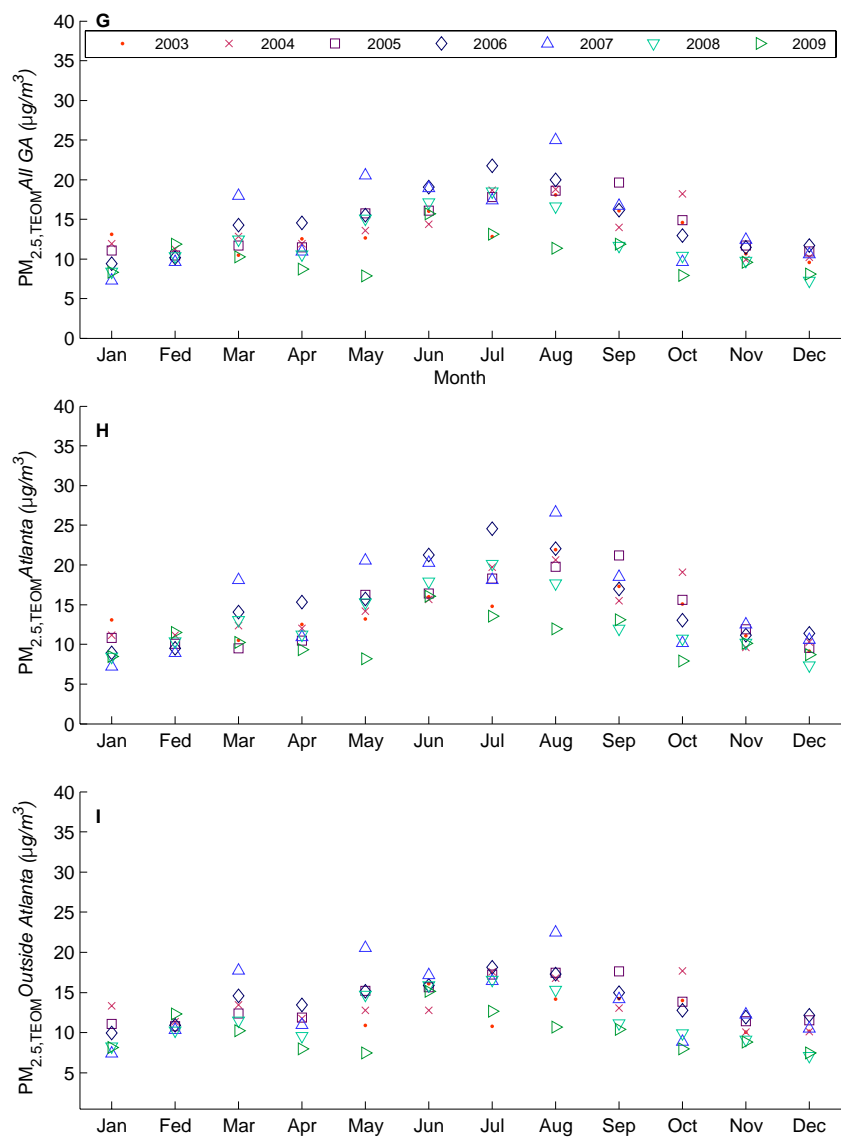

Fig. 3c. (G-I) Multi-year plots of monthly means for $\mathrm{PM}_{2.5, \mathrm{TEOM}}$ All GA, $\mathrm{PM}_{2.5, \mathrm{TEOM}}$ Atlanta and

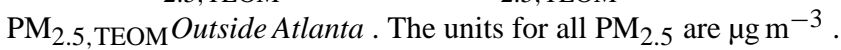

ferences in sampling and regional averaging between satellite imagery and ground sites might be a factor. The persistent presence of an aerosol layer aloft during the summer, as suggested by Goldstein et al. (2009), will also contribute to differences between AOD and $\mathrm{PM}_{2.5}$. However, our analysis of CALIPSO lidar profiles does not reveal the frequent occurrences of aerosol layers aloft, with the exception of wildfire smoke (Alston and Sokolik, 2012).

Further, we examine the behaviour of seasonal means. Here each season is defined in standard Northern Hemisphere fashion: winter (December, January and February), spring (March, April and May), summer (June, July and August), and fall (September, October and November). Figure 4 presents the comparison of AODs. In most locations, MODIS reports higher AOD values than MISR. Although Fig. 3a show that on a monthly basis the differences between the two sensors are smallest during the fall and winter, our seasonal analysis (Fig. 4) shows more variance between the sensors. Not surprisingly, the linear regression slopes $(0.33$ for winter and 0.54 for fall) are not close to 1 , and the subsequent correlation coefficients are 0.33 and 0.57 , respectively. 

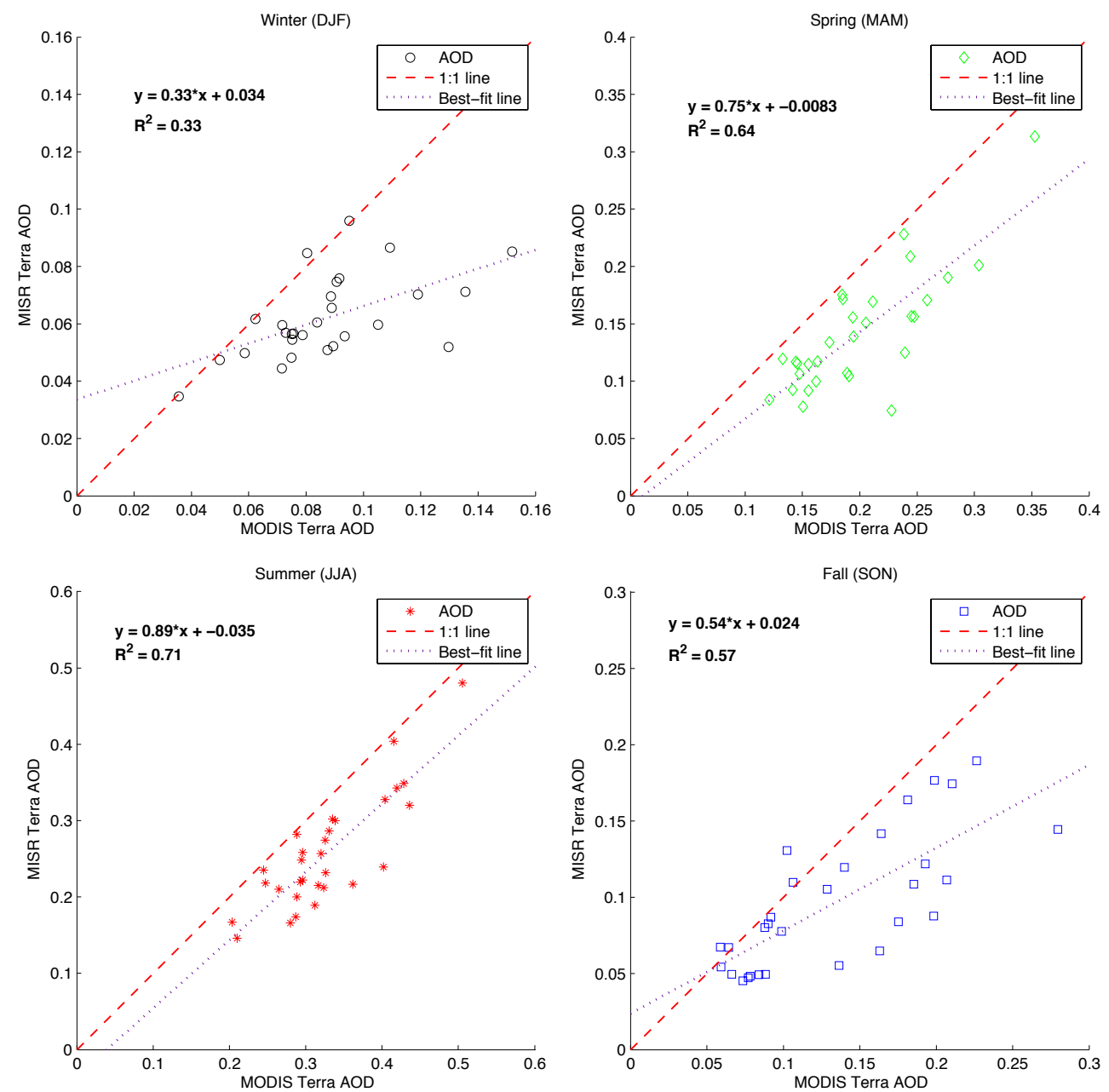

Fig. 4. Seasonal scatterplots of MODIS Terra AOD vs. MISR Terra AOD. Red dashed line denotes 1:1. Purple dotted line denotes linear regression line.

The outliers in scatterplots are possibly due to retrieval biases, differences within the retrieval algorithms, differences in spatial sampling, and cloud effects. Remer et al. (2008) found that on a global scale, AOD in situations with $80 \%$ cloud fraction are twice the global mean of AOD values, although this occurred less than $1 \%$ of the time over land; however, they note that AOD values near clouds can double the reported AOD due to subpixel cloud contamination (Zhang et al., 2005), 3-D effects (Wen et al., 2007), and increase of AOD due to increased humidity near clouds (Koren et al., 2007). Kahn et al. (2009) found that MODIS AOD values are lower than MISR AOD values for AOD below 0.2, which could be related to Collection 5 algorithm changes that allow for negative AOD retrievals. The spring and summer seasons produce the greatest agreement between the two sensors with correlation coefficients of 0.64 and 0.71 , respectively. Hygroscopic growth of aerosols due to higher relative humidity in the summer also possibly influence the agreement between the sensors. An additional influence could be the weather pattern dynamics with the spring and summer seasons experiencing large-scale high pressure systems that can persist, which likely results in increased AOD values for both sensors despite their differences in viewing geometry. Interestingly, the signs of the y-intercepts are negative for spring and summer seasons. Possible explanations for this include that we do not force our linear regressions through zero, and due to systematic underestimation of AOD by MISR (Kahn et al., 2009), the regression line is pulled downward. Nevertheless, our results suggest good agreement between the two sensors over the past ten years. Yet Liu and Mishchenko (2008) reported larger disparities between the two. We should note that Liu and Mishchenko (2008) only consider two months (January and July) from 2006, and they consider a region (Eastern US) that is spatially larger than our area and contains multiple sources of aerosols (e.g., large metropolitan area). In contrast, our study region only contains one large metropolitan area, i.e., Atlanta. 

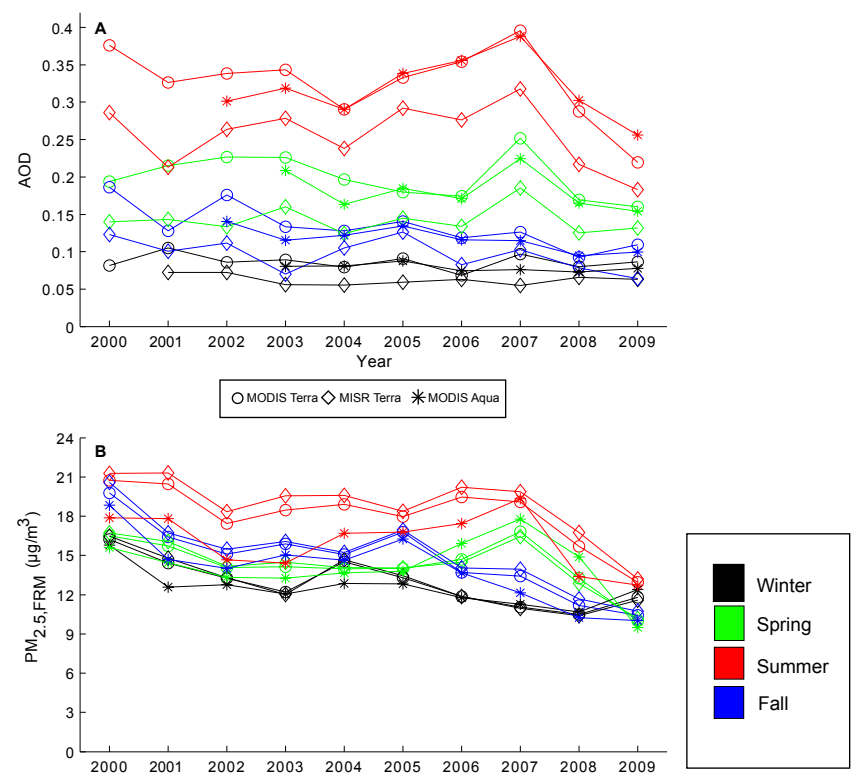

$O \mathrm{PM}_{2.5, \mathrm{FRM}}$ All GA $\diamond \mathrm{PM}_{2.5, \mathrm{FRM} \text { Atlanta }} * \mathrm{PM}_{2.5, \mathrm{FRM} \text { Outisde Atanta }}$

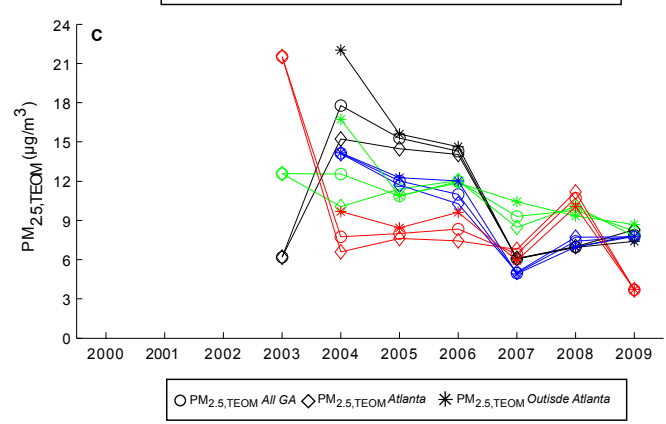

Fig. 5. (A) Time series of seasonal means for MODIS Terra AOD, MISR Terra AOD and MODIS Aqua AOD. (B) Same as (A) except for $\mathrm{PM}_{2.5, \mathrm{FRM}}$ All GA, $\mathrm{PM}_{2.5 \text {, FRM Atlanta }}$ and $\mathrm{PM}_{2.5, \mathrm{FRM}}$ Outside Atlanta. (C) Same as (A) except for $\mathrm{PM}_{2.5}, \mathrm{TEOM}$ All GA, $\mathrm{PM}_{2.5, \mathrm{TEOM}}$ Atlanta and $\mathrm{PM}_{2.5}$, TEOM Outside Atlanta. The units for all $\mathrm{PM}_{2.5}$ are $\mu \mathrm{g} \mathrm{m}^{-3}$.

Figure 5 shows how the seasonal means for each dataset change over time. As expected, spring and summer seasons show the most variance over the years. For instance, in the year 2000 MODIS Terra and MISR Terra had summer AOD means of 0.38 and 0.29 , respectively, and by 2009 the means were 0.21 and 0.24 . Also, even though our considered domain is relatively small $\left(5^{\circ}\right.$ by $\left.5^{\circ}\right)$, our seasonal means are similar in behaviour to those of Northeast America as shown in Remer et al. (2008) where Level $31^{\circ} \times 1^{\circ}$ globally gridded AOD are used for regional seasonal analysis; moreover, our seasonal means are higher. In the $\mathrm{PM}_{2.5}$ datasets there appear to be different behaviours. The $\mathrm{PM}_{2.5}$,FRM values all appear to be decreasing with time. In $2000, \mathrm{PM}_{2.5}$,FRM concentrations were around $22 \mu \mathrm{g} \mathrm{m}^{-3}$, but by the end of the decade they had decreased to around $14 \mu \mathrm{g} \mathrm{m}^{-3}$. The spring, fall, and winter seasons have similar behaviours, with sum- mer being the exception. The three seasons also show similar behaviour across all of Georgia, yet during the summer our results suggest that Atlanta is dominating concentrations across the state. The difference between the All GA and Atlanta means at most varied around $2 \mu \mathrm{g} \mathrm{m}^{-3}$, and there is a larger difference $\left(4 \mu \mathrm{g} \mathrm{m}^{-3}\right)$ between the All GA means and the Outside Atlanta means. Alston et al. (2011) highlighted how spring 2007 was anomalous in both AOD and $\mathrm{PM}_{2.5}$ concentrations compared with other springs due to the large wildfire that burned for almost two months. It is likely that if the wildfire had not occurred, the spring means would decrease with time. Despite increased means for 2006 and 2007, the $\mathrm{PM}_{2.5}$,TEOM dataset appears to generally decrease with time as discussed below.

The aerosol seasonality was also examined through an analysis of satellite AOD fields over the past $10 \mathrm{yr}$. In particular, we were interested in understanding if there are any discernible AOD differences from the large metropolitan area of Atlanta and the remainder of the state. Seasonal maps of AOD from MODIS Terra and MISR Terra are shown in Fig. 6: winter mean AOD (A and D), summer mean AOD (B and $\mathrm{E}$ ), and the difference between the two seasons in ( $\mathrm{C}$ and F). In the summer and difference plots of Fig. 6, the smallest values of AOD are represented by blue colors; to contrast the small values of the winter means with the summer means we chose to plot the winter means with a blue scale. These maps, specifically the seasonal difference maps, provide comparison to similar figures in Goldstein et al. (2009) (see their Fig. 1). Our spatial analysis does not strongly resemble the features seen in Goldstein et al. (2009), namely the large area of AOD (AOD > 0.25) over the broader Southeastern US. It should be noted that a major difference between this study and theirs is that we use a finer resolution product (Level 2), which is gridded to finer resolution grid than is provided by the Level $3\left(1^{\circ} \times 1^{\circ}\right)$ monthly mean product used by Goldstein et al. (2009). The Level 3 products produces smoother appearing maps that can likely mask large point sources (e.g., industrialization, large metropolitan areas). This study also uses data from 2000-2009, whereas their study encompassed 2000-2007.

The MODIS maps suggest that the Atlanta area has slightly higher AOD from the remainder of the region (see Fig. 6, A-C). The MISR maps do not appear to capture the AOD signal in Atlanta as well as MODIS (see Fig. 6, D-F); however, both sensors show very low AOD during the winter season with AOD values $<0.1$, though there are some areas near the coastlines and over the ocean where AOD $>0.1$. This difference can be explained, to some extent, by bias over coastline areas (Chu et al., 2002; Kahn et al., 2007; Levy et al., 2005). The summer season presents a more varied spatial representation. As noted early, there is almost a $3 \times$ increase from winter AOD values. One common feature between the sensors is that the region immediately outside Atanta appears fairly uniform in AOD. The difference plots (Fig. 6, C and F) suggest variation across the region that is 
A. Winter Mean MODIS AOD

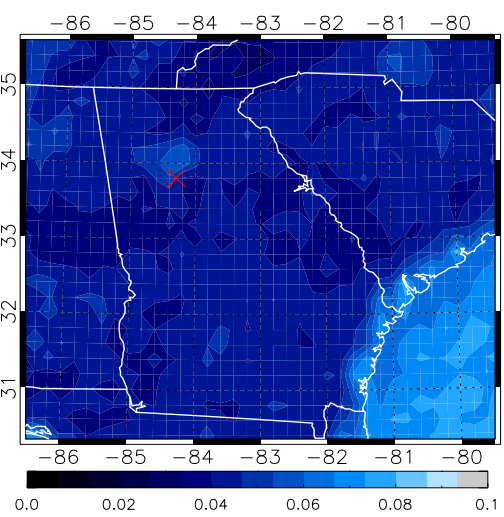

D. Winter Mean MISR AOD

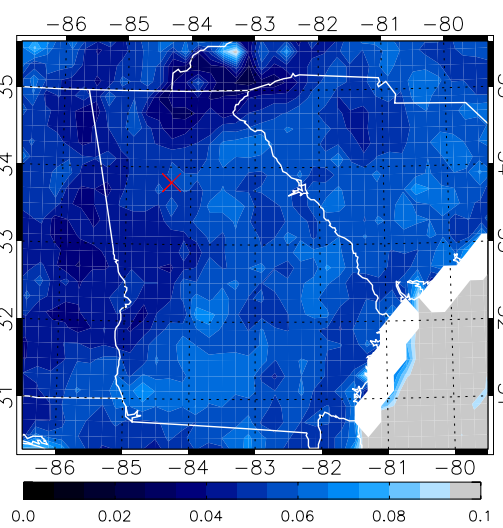

B. Summer mean MODIS AOD

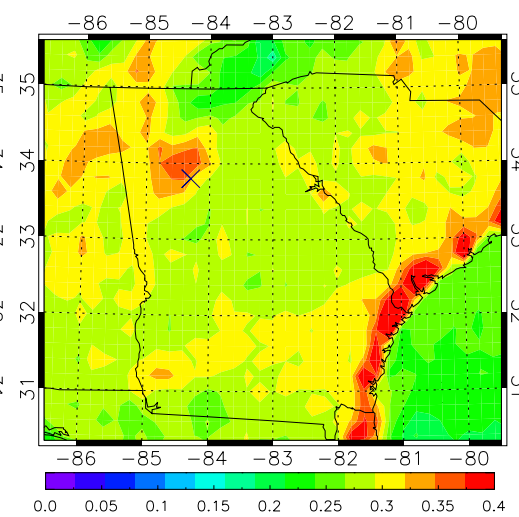

E. Summer mean MISR AOD

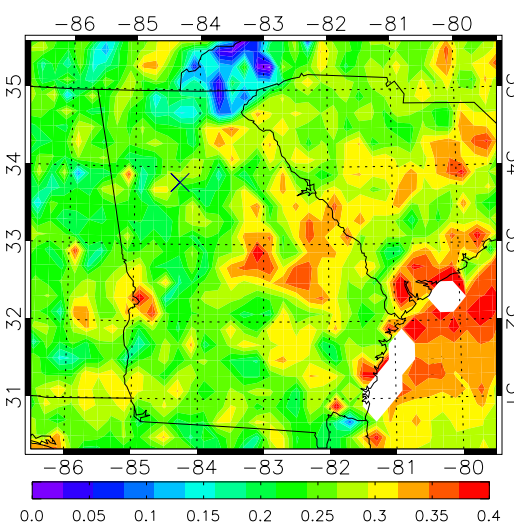

C. Difference $=$ Summer - Winter MODIS

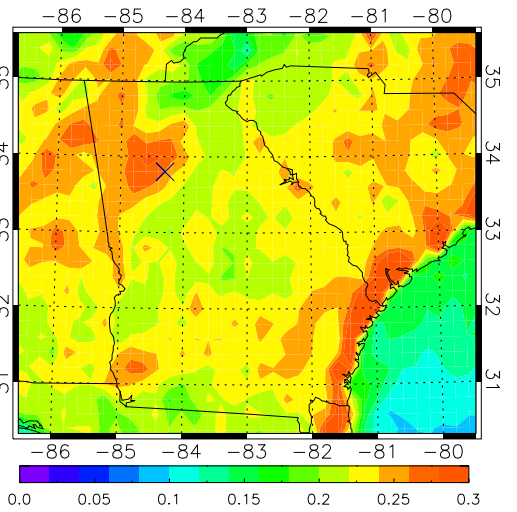

F. Difference $=$ Summer - Winter MISR

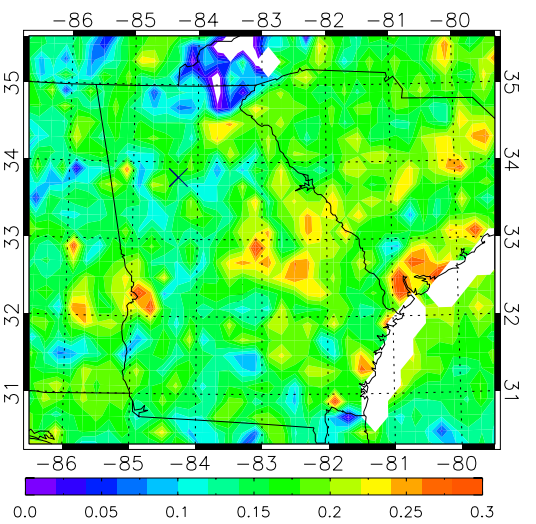

Fig. 6. Maps of satellite AOD. (A) Winter mean AOD for MODIS Terra. (B) Summer mean AOD for MODIS Terra. (C) Difference between summer mean AOD minus winter mean AOD for MODIS Terra. (D) Same as (A) except for MISR Terra. (E) Same as (B) except for MISR Terra. (F) Same as (C) except for MISR Terra. In (A and D) the red "X" denotes Atlanta, GA. In (B-C and E-F) the navy "X" denotes Atlanta, GA.

not seen in Fig. 1 of Goldstein et al. (2009). In summary, the spatial analysis presented here shows some differences between Atlanta and the remainder of the region, at least from the MODIS Terra perspective, and this analysis shows more variability in seasonality in spatial extent and magnitude than previously shown by Goldstein et al. (2009). Finer scale spatial resolution of satellites will likely aid the differentiation of urban centers from background conditions. Until newer satellite products are available with finer resolution, regional scale analysis will remain the current standard.

\subsection{Inter-annual variability and trends}

To examine inter-annual variability of aerosols in the Southeast US, we analyzed monthly means of satellite AOD and ground based $\mathrm{PM}_{2.5}$ data, including analyses of anomalies and trends. Figure 7 presents the time series of monthly mean AODs for MODIS Terra, MISR Terra, and MODIS Aqua, along with time series of monthly mean $\mathrm{PM}_{2.5}$ concentrations for the two ground datasets. When viewed over the past ten years, the satellites have generally good agreement with each other. Though there are differences in AOD magnitudes between MODIS Terra and MISR Terra, their behaviour over time is quite similar. The difference between minima $(\approx 0.1)$ and maxima $(\approx 0.4)$ for the MODIS sensors is about 0.3 . In other words, according to the MODIS sensor, AOD almost quadruples from the lowest values in winter to the highest values in summer. MISR appears to have quite dramatic fluctuations as well, with its minima $\approx 0.3$ and its maxima $\approx 0.8$. The inter-annual variability makes it difficult to determine if there is a trend over time.

In contrast, the $\mathrm{PM}_{2.5}$ datasets show a distinctly decreasing trend over time. Both the maxima and minima for these datasets have decreased by $5-8 \mu \mathrm{g} \mathrm{m}^{-3}$. The seasonality is present in the $\mathrm{PM}_{2.5}$ datasets, but not as pronounced as the AOD datasets. When viewed together (both AOD and $\mathrm{PM}_{2.5}$ datasets), the peaks and valleys in the time series correspond well together. For instance, the correlation coefficient of MODIS Terra vs. $\mathrm{PM}_{2.5, \mathrm{FRM}}$ All GA and MISR Terra vs. $\mathrm{PM}_{2.5, \text { FRM }} A l l G A$ is 0.72 and 0.73 , respectively; however, the correlation coefficient of MODIS Aqua vs. $\mathrm{PM}_{2.5, \mathrm{FRM}} A l l G A$ is 0.8 . Correlation analysis 

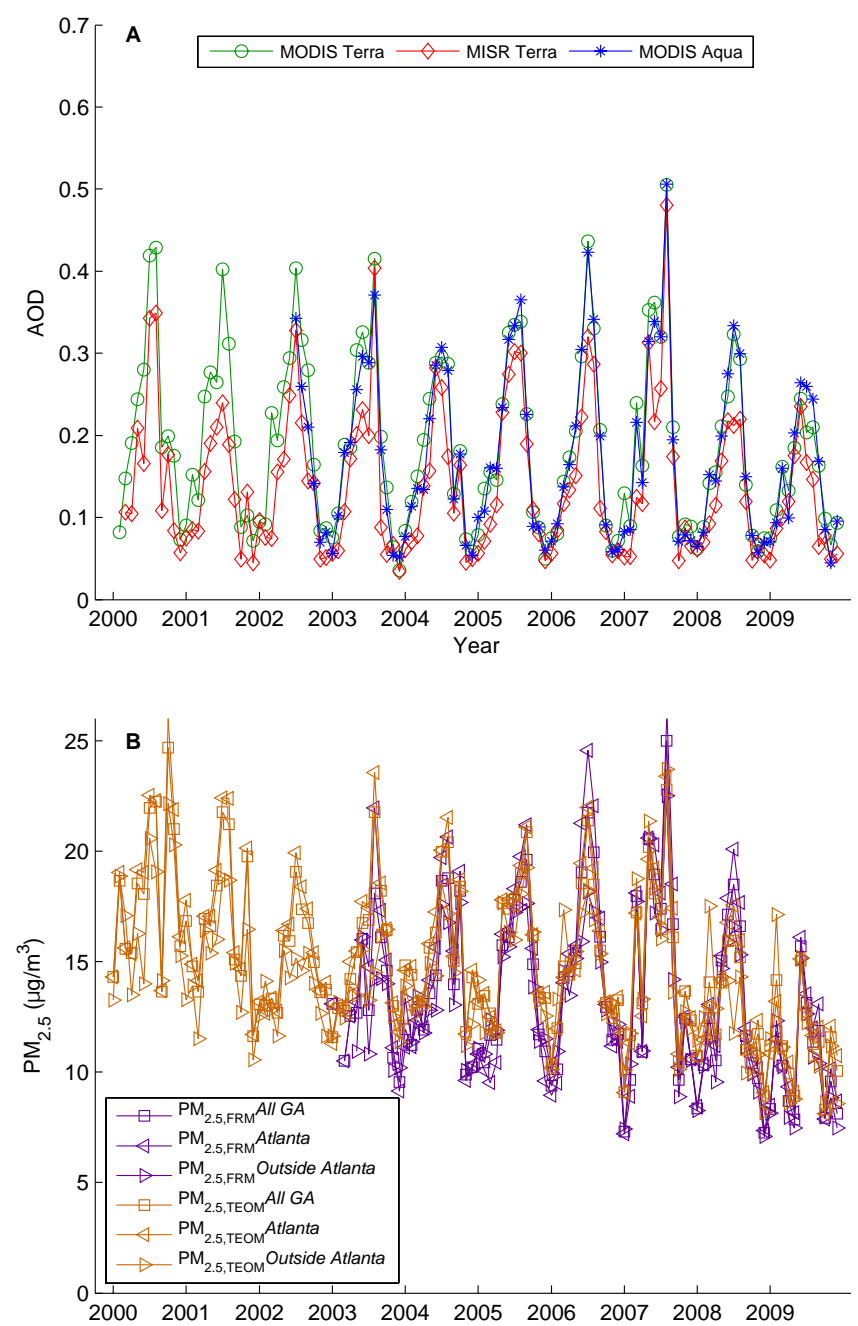

Fig. 7. Time series of monthly means for satellite AOD and $\mathrm{PM}_{2.5}$ datasets. The units for all $\mathrm{PM}_{2.5}$ are $\mu \mathrm{g} \mathrm{m}{ }^{-3}$.

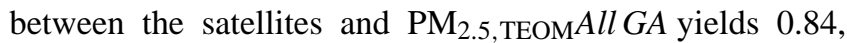
0.81 and 0.84 , respectively. Finally, Fig. 8 presents AOD and $\mathrm{PM}_{2.5}$ concentrations over the past $10 \mathrm{yr}$ in terms of yearly means calculated from monthly means. These datasets may indicate a decreasing trend with time, with the

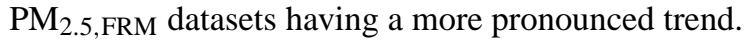

The first step in the determination of a trend is to fit the time series with a linear regression. The second step is to access if the slope is statistically different from zero by using t-test for $\alpha=0.05$. Though there was no trend easily detected in Fig. 7, we fit each satellite AOD with a linear regression and determined that all the datasets did not have a statistically significant slope. As mentioned earlier, the $\mathrm{PM}_{2.5}$ datasets appear to be decreasing with time. The linear regression for $\mathrm{PM}_{2.5 \text {,FRM }}$ all have slopes that are significant for $\alpha=0.05$. In other words, the detected decrease in the time series is valid with some certainty. The $\mathrm{PM}_{2.5 \text {,TEOM datasets have more varied results. The slopes }}$
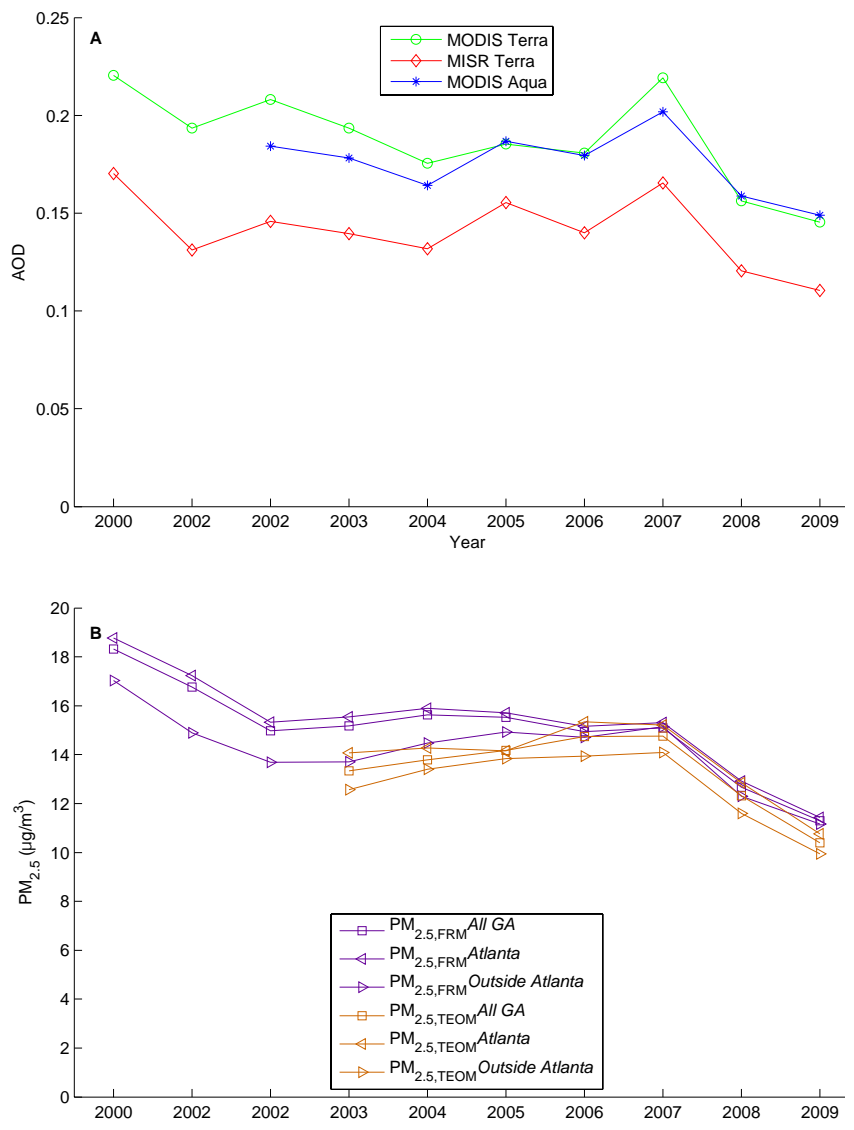

Fig. 8. Time series of multi-year means for satellite AOD and $\mathrm{PM}_{2.5}$ datasets. The units for all $\mathrm{PM}_{2.5}$ are $\mu \mathrm{g} \mathrm{m}^{-3}$.

for $\mathrm{PM}_{2.5, \mathrm{TEOM}} A l l$ GA and $\mathrm{PM}_{2.5, \mathrm{TEOM}}$ Atlanta are not statistically significant, yet $\mathrm{PM}_{2.5}$,TEOMOutside Atlanta is significant. Our previous results suggest that metropolitan area of Atlanta concentrations likely skew the statewide average towards higher values due to the majority of the TEOM monitors $(7$ or $60 \%)$ being in the metropolitan area of Atlanta. Our results also hint that the rest of the state is indeed experiencing decreasing $\mathrm{PM}_{2.5}$ concentrations, but the anthropogenic emissions especially in the summer in the metropolitan area of Atlanta are likely masking this decreasing trend. Another possible explanation for why one $\mathrm{PM}_{2.5}$ dataset shows a decreasing trend and the other does not is the difference in length of the data records.

Ultimately, it is necessary to remove the seasonal signal in order to assess the presence of any true trends. We calculate a ten-year mean of every month, and subtract each month from the 10-yr mean of that month. For example, if the ten-year January average is 0.18 , then 0.18 is subtracted from each January in the dataset, thus we are using anomalies from the 10-yr monthly mean to detect trends over the past $10 \mathrm{yr}$. The resulting time series of anomalies for both satellite and $\mathrm{PM}_{2.5}$ datasets are shown in Fig. 9a-9c. There appears to be some correlation between the satellite 

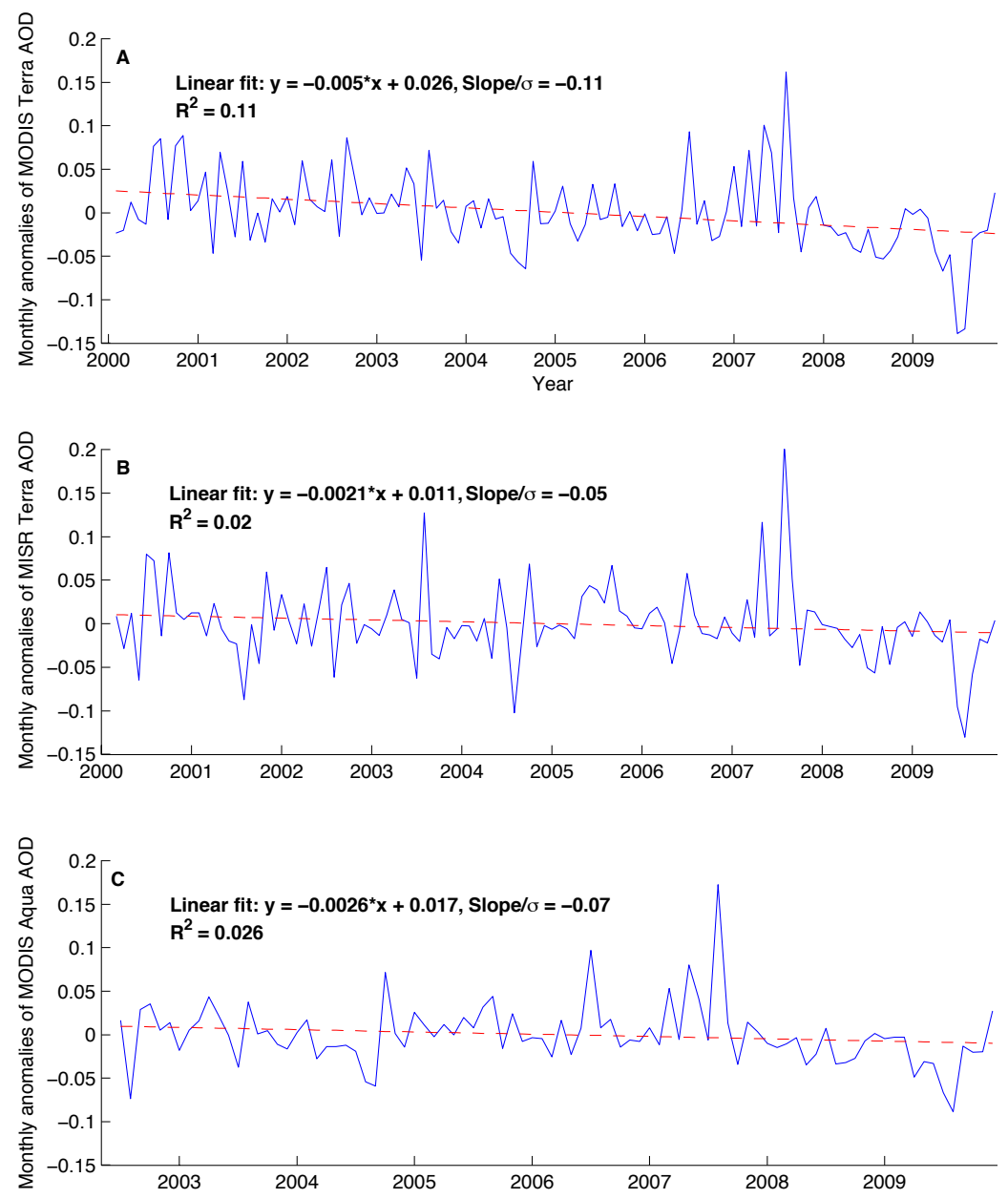

Fig. 9a. (A-C) Time series of monthly anomalies for MODIS Terra AOD, MISR Terra AOD, and MODIS Aqua AOD. Dashed red lines denote linear regression trend lines (see Table 1). Linear regression equations, linear fit statistics and normalized slopes $=$ slope/standard deviation $(\sigma)$ are inset.

AOD datasets with the $\mathrm{PM}_{2.5 \text {,FRM }}$ All $G A$ dataset, where the correlations values for MODIS Terra, MISR and MODIS Aqua are $0.64,0.55$ and 0.63 , respectively. We also calculated correlation values using the same satellite datasets vs. $\mathrm{PM}_{2.5, \text { TEOM }} A l l G A$; the correlations being $0.66,0.6$ and 0.7 , respectively. The anomaly time series are fit with linear regressions to determine the trend and are shown by the dashed line in Fig. 9. We calculated the slope in terms of changes per year, and all of the $\mathrm{PM}_{2.5}$ datasets show negative trends, which are statistically significant at the $\alpha=0.05$ confidence level. The trend for MODIS Terra anomaly data was significant as well. We believe that the primary reason that the other datasets of the satellites do not show a significant trend is due to the shortness of the data records. Removing the outlier points outside the $2 \sigma$ range has negligible effect on the slope. Table 1 summarizes the linear regression variables (slope and y-intercept) for monthly mean time series and anomalies time series for each dataset. In addition, Fig. 9 shows the values of normalized slope, i.e., the ratio of slope to standard deviation $(\sigma)$. This allows for direct comparisons between the different datasets. The normalized slopes for the $\mathrm{PM}_{2.5}$ monthly anomalies range from -0.14 to -0.21 , while the normalized slopes of AOD are smaller with MODIS Terra $=-0.11$, MISR $=-0.05$ and MODIS Aqua $=-0.07$. The factors contributing to the differences in seasonal cycle (see Sect. 3.1) can also be responsible for observed differences among trends.

\section{Conclusions and discussion}

We analyzed aerosol data from both ground based $\left(\mathrm{PM}_{2.5}\right)$ and space based (satellite AOD) platforms in order to examine the seasonality and inter-annual variations of the regional aerosol signal, and to detect if there was any discernable trends over the past ten years. We found that strong seasonality exists in both the AOD and $\mathrm{PM}_{2.5}$ datasets where mean summertime AOD is nearly three times higher than mean wintertime AOD, and mean summertime 

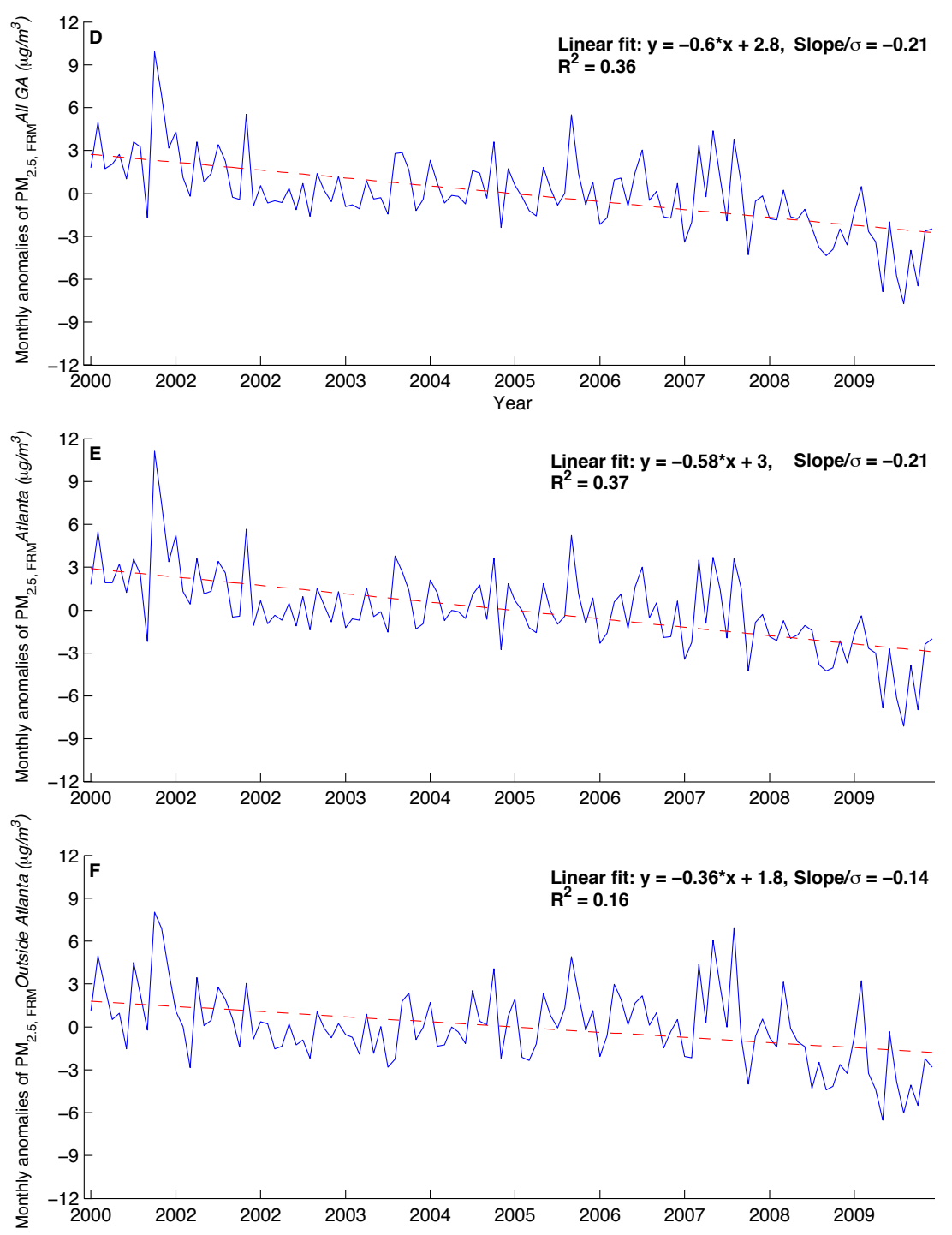

Fig. 9b. (D-F) Time series of monthly anomalies for $\mathrm{PM}_{2.5}, \mathrm{FRM}^{A}$ All GA, $\mathrm{PM}_{2.5}, \mathrm{FRM}$ Atlanta and $\mathrm{PM}_{2.5}$,FRMOutside Atlanta . The units for all $\mathrm{PM}_{2.5}$ are $\mu \mathrm{g} \mathrm{m}^{-3}$. Dashed red lines denote linear regression trend lines (see Table 1). Linear regression equations, linear fit statistics and normalized slopes $=$ slope $/$ standard deviation $(\sigma)$ are inset.

$\mathrm{PM}_{2.5}$ concentrations are almost twice as high as mean wintertime concentrations. Another factor that possibly influences the seasonality is the effect of hygroscopic aerosol growth during the summer months, given higher relative humidity in the summer. Though satellite retrieval algorithms do not directly incorporate relative humidity, the retrievals are affected (Wang and Martin, 2007). Additionally over the past ten years, the $\mathrm{PM}_{2.5}$ dataset used for regulatory purposes $\left(\mathrm{PM}_{2.5, \mathrm{FRM}}\right)$ agrees quite well with the satellite AOD measurements. The correlation coefficients between

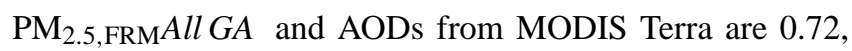
for MISR Terra are 0.73 , and for MODIS Aqua are 0.8 .

We found that MODIS onboard Terra and MISR onboard Terra agree well with each other during the warmer months with correlation coefficients of 0.67 for spring and 0.71 for summer. It is possible that cloud cover and inherent differences in sensor sensitivity explain the reduced agreement during the cooler months. Trend analysis was performed to establish baselines of different aerosol measures. We use t-tests of the slopes for $\alpha=0.05$ to determine whether the calculated slopes are statistically different from zero. Given the strong seasonality, we removed the seasonal component to create monthly mean anomalies. Trend analysis of the monthly mean anomalies yielded that MODIS onboard Terra has a statistically significant negative trend, and all the $\mathrm{PM}_{2.5}$ datasets have statistically significant negative trends. There are correlations between the detrended $\mathrm{PM}_{2.5, \mathrm{FRM}} A l l G A$ datasets and the detrended satellite AOD 

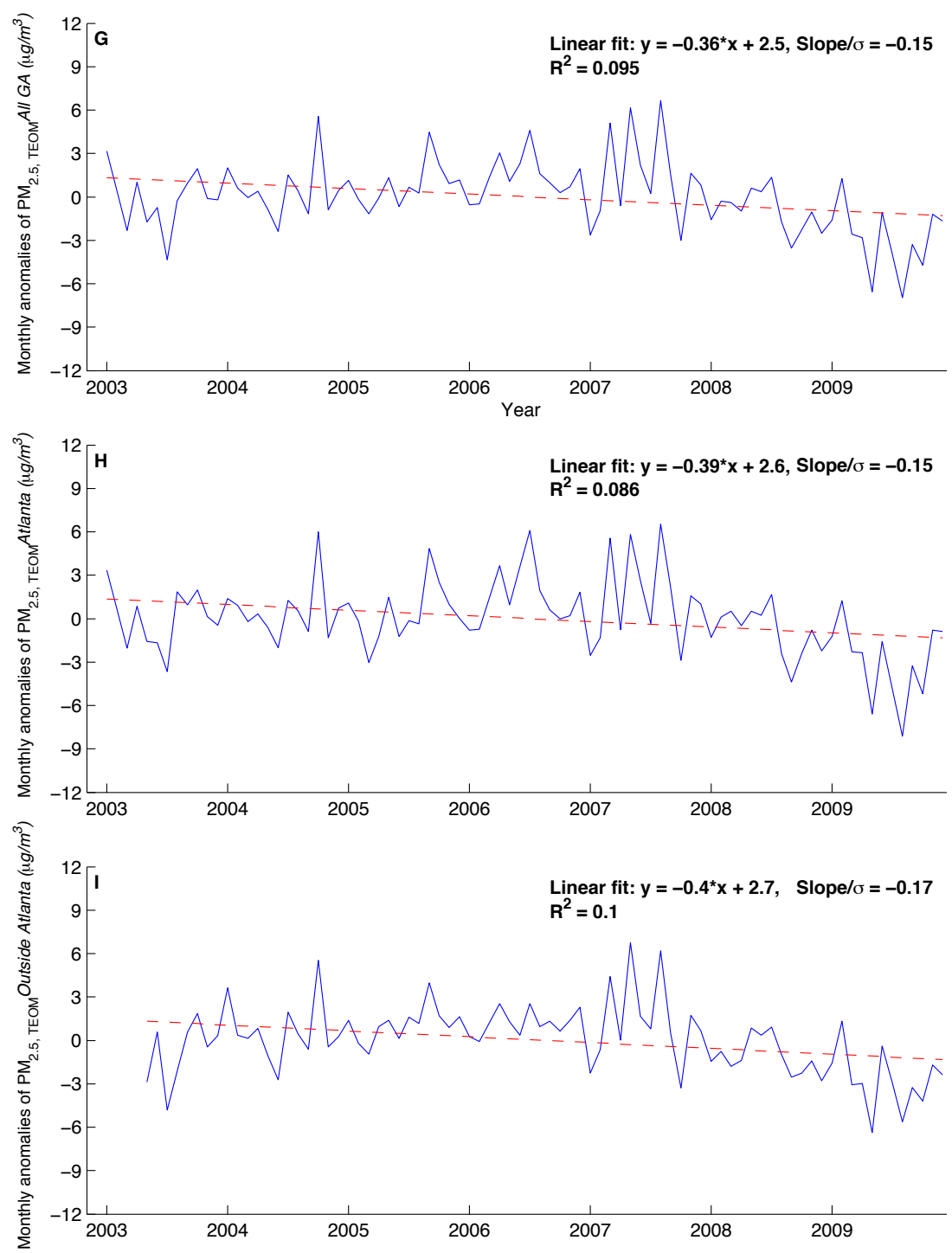

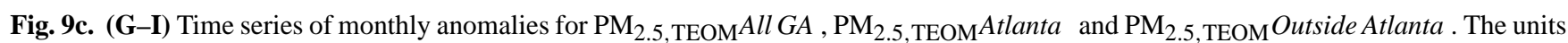
for all $\mathrm{PM}_{2.5}$ are $\mu \mathrm{g} \mathrm{m}^{-3}$. Dashed red lines denote linear regression trend lines (see Table 1). Linear regression equations, linear fit statistics and normalized slopes $=$ slope $/$ standard deviation $(\sigma)$ are inset.

datasets, where the AOD datasets vs. $\mathrm{PM}_{2.5, \mathrm{FRM} A l l G A \text { had }}$ correlations of 0.64 for MODIS Terra, 0.55 for MISR, and 0.63 for MODIS Aqua. It should be noted that for MODIS onboard Terra, this detected trend could be impacted by degradation of the blue channel used in MODIS retrievals over land, yet even with this drift taken into account the retrieved values are within the acceptable error envelope (Kahn et al., 2011; Levy et al., 2010).

Our results do not support fully the Goldstein et al. (2009) hypothesis of a dominant contribution of SOA from biogenic emission to summer AODs in the region. AOD is a columnaveraged measurement that cannot be readily differentiated between sources without additional information. One piece of supporting evidence for the Goldstein et al. (2009) hy- pothesis was based on the similarity between summer AOD patterns and BVOC emission patterns. Caution must be exercised, however, since the choice of spatial resolution (e.g., Level 2 vs. Level 3) of AOD products may be important (see Sect. 3.2). The spatial analysis presented here agrees only partially with that shown in Goldstein et al. (2009). Of significance is that our results are different in spatial features (not smooth continuous fields of AOD) and magnitude (the difference between summer and winter is higher).

Another facet of the Goldstein et al. (2009) hypothesis is that BVOC associated SOA are formed in an aerosol layer aloft in summer, so that ground based sensors would not likely capture these BVOC SOA. However, chemical speciation of speciation of $\mathrm{PM}_{2.5}$ does show a significant SOA 
Table 1. Linear regression coefficients for satellite and $\mathrm{PM}_{2.5}$ datasets. Significance for $\alpha=0.5$ is denoted in bold. Intercept values are given

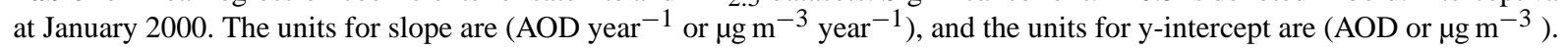

\begin{tabular}{|c|c|c|c|c|}
\hline \multirow{2}{*}{ Dataset } & \multicolumn{2}{|c|}{ Slope } & \multicolumn{2}{|c|}{ Y-intercept } \\
\hline & Values & Anomalies & Values & Anomalies \\
\hline MODIS Terra & -0.0056 & -0.0050 & 0.214 & 0.025 \\
\hline MISR Terra & -0.0028 & -0.0021 & 0.15 & 0.11 \\
\hline MODIS Aqua & -0.0033 & -0.0026 & 0.196 & 0.17 \\
\hline $\mathrm{PM}_{2.5, \mathrm{FRM}} A l l G A$ & -0.54 & -0.58 & 17.75 & 2.781 \\
\hline $\mathrm{PM}_{2.5, \mathrm{FRM}}$ Atlanta & -0.57 & -0.58 & 18.187 & 2.951 \\
\hline $\mathrm{PM}_{2.5, \mathrm{FRM}}$ Outside Atlanta & -0.36 & -0.36 & 16.029 & 1.821 \\
\hline $\mathrm{PM}_{2.5, \mathrm{TEOM}}$ All GA & -0.38 & -0.39 & 15.876 & 2.501 \\
\hline $\mathrm{PM}_{2.5, \mathrm{TEOM}}$ Atlanta & -0.38 & -0.39 & 16.325 & 2.561 \\
\hline $\mathrm{PM}_{2.5, \mathrm{TEOM} O u t s i d e}$ Atlanta & -0.46 & -0.40 & 15.876 & 2.696 \\
\hline
\end{tabular}

fraction, but given the current state of measurement techniques it is not a simple exercise to differentiate between SOA of anthropogenic and biogenic sources (Weber et al., 2007). Additionally, our preliminary analysis of CALIPSO lidar data during the winter and summer seasons does not reveal a persistent aerosol layer aloft over this region (Alston and Sokolik, 2012). CALIPSO data show that if there was an aerosol layer, it appeared to be wholly within the PBL as it usually started at the surface and expanded to a height of $1-2.5 \mathrm{~km}$ depending on the season. Also, the persistent presence of a layer of SOA aloft is not supported by measurements from recent aircraft field campaigns (Heald et al., 2011). Of course, this requires additional measurements of aerosol profiles in this region for confirmation purposes.

If we assume that the emission rate of BVOC is primarily temperature driven, then if the temperature record was found to neither increase or decrease (Menne et al., 2009), the biogenic SOA is unlikely to be the sole driver behind the negative trends in AOD. Following this reasoning the primary driver behind the negative trend appears likely to be anthropogenic sources, which are monitored and controlled through air quality policies. Thus, our analysis suggests that air quality policies and controls placed upon $\mathrm{PM}_{2.5}$ precursors may have resulted in appreciated decreases in aerosols in the US Southeast. Our results also suggest that this region is experiencing solar brightening associated with decreasing concentrations of aerosols. Ground-based measurements of solar irradiance in the region would be necessary to confirm our conclusions. Currently, there is no such monitoring being done.

Our analysis also provides a useful baseline for naturally derived aerosols representative of background conditions in this region of the US. Establishing the background helps to delineate the $\mathrm{PM}_{2.5}$ contributions of the metropolitan area of Atlanta. Thus, it is likely that future air quality control strategies will need to focus upon the anthropogenic component, while also incorporating naturally occurring aerosols.
Additionally, the air quality control policies that have likely resulted in solar brightening might have potential climatic trade-offs. As such, these longer-term analyses are critical for evaluation of the air pollution regulatory policies, and these analyses can serve as baselines of measures that can be used to access impacts of future policies and climate change. The methodology applied here is readily applicable to regions that have sufficient ground-based aerosol measurements so long as the chosen area is large enough for sufficient satellite coverage. The need for finer scale resolution satellite sensors will aid a host of applications seeking to do more detailed regional and local scale analyses. Users of satellite data need to be aware of possible bias within the data at land-water boundaries, which is an important consideration given that so many highly populated areas are near coasts. It is possible that with newer sensors, better treatment of these issues will be addressed. Our future work will focus upon the climatic impacts of the decreasing aerosol trend on this region (Alston and Sokolik, 2012).

Acknowledgements. E. J. Alston would like to thank the Science Directorate, NASA LaRC for its support, and Bruce G. Doddridge for his helpful discussions. I. N. Sokolik acknowledges partial support from the Radiation Sciences Programs. We thank the MISR team for providing access to data, and useful discussions. This work was partially performed at the Jet Propulsion Laboratory, California Institute of Technology, under contract with NASA. The authors wish to thank the referees for the time and insightful feedback that has strengthened this publication.

Edited by: F. Boersma 


\section{References}

Alpert, P. and Kischa, P.: Quantification of the effect of urbanization on solar dimming, Geophys. Res. Lett., 35, L08801, doi:10.1029/2007GL033012, 2008.

Alpert, P., Kishcha, P., Kaufman, Y. J., and Schwarzbard, R.: Global dimming or local dimming?: Effect of urbanization on sunlight availability, Geophys. Res. Lett., 32, L17802, doi:10.1029/2005g1023320, 2005.

Alston, E. J. and Sokolik, I. N.: A first-order radiative forcing assessment based on decadal satellite data in the US Southeast, in preparation, 2012.

Alston, E. J., Sokolik, I. N., and Doddridge, B. G.: Investigation into the use of satellite data in aiding characterization of particulate air quality in the Atlanta, Georgia metropolitan area, J. Air Waste Manage., 61, 211-225, doi:10.3155/1047-3289.61.2.211, 2011.

Carrico, C. M., Bergin, M. H., Xu, J., Baumann, K., and Maring, H.: Urban aerosol radiative properties: Measurements during the 1999 Atlanta Supersite Experiment, J. Geophys. Res., 108, 8422, doi:10.1029/2001JD001222, 2003.

Chu, D. A., Kaufman, Y. J., Ichoku, C., Remer, L. A., Tanré, D., and Holben, B. N.: Validation of MODIS aerosol optical depth retrieval over land, Geophys. Res. Lett., 29, 1617, doi:10.1029/2001GL013205, 2002.

Diner, D. J., Beckert, J. C., Bothwell, G. W., and Rodriguez, J. I.: Performance of the MISR instrument during its first 20 months in Earth orbit, IEEE T. Geosci. Remote, 40, 1449-1466, 2002.

Dutton, E. G., Nelson, D. W., Stone, R. S., Longenecker, D., Carbaugh, G., Harris, J. M., and Wendell, J.: Decadal variations in surface solar irradiance as observed in a globally remote network, J. Geophys. Res., 111, D19101, doi:10.1029/2005jd006901, 2006.

Edgerton, E. S., Hartsell, B. E., Saylor, R. D., Jansen, J. J., Hansen, D. A., and Hidy, G. M.: The Southeastern Aerosol Research and Characterization Study: Part II. Filter-based measurements of fine and coarse particulate matter mass and composition, J. Air Waste Manage., 55, 1527-1341, 2005.

Engel-Cox, J. A., Holloman, C. H., Coutant, B. W., and Hoff, R. M.: Qualitative and quantitative evaluation of MODIS satellite sensor data for regional and urban scale air quality, Atmos. Environ., 38, 2495-2509, doi:10.1016/j.atmosenv.2004.01.039, 2004.

Gilgen, H., Roesch, A., Wild, M., and Ohmura, A.: Decadal changes in shortwave irradiance at the surface in the period from 1960 to 2000 estimated from Global Energy Balance Archive Data, J. Geophys. Res., 114, D00D08, doi:10.1029/2008jd011383, 2009.

Goldstein, A. H., Koven, C. D., Heald, C. L., and Fung, I. Y.: Biogenic carbon and anthropogenic pollutants combine to form a cooling haze over the southeastern United States, Proc. Natl. Acad. Sci. USA, 106, 8835-8840, doi:10.1073/pnas.0904128106, 2009.

Gupta, P. and Christopher, S. A.: Seven year particulate matter air quality assessment from surface and satellite measurements, Atmos. Chem. Phys., 8, 3311-3324, doi:10.5194/acp-8-3311-2008, 2008.

Gupta, P. and Christopher, S. A.: Particulate matter air quality assessment using integrated surface, satellite, and meteorological products: Multiple regression approach, J. Geophys. Res., 114, D14S07, doi:10.1029/2008JD011496, 2009.

Heald, C. L., Coe, H., Jimenez, J. L., Weber, R. J., Bahreini, R., Middlebrook, A. M., Russell, L. M., Jolleys, M., Fu, T.-M., Al- lan, J. D., Bower, K. N., Capes, G., Crosier, J., Morgan, W. T., Robinson, N. H., Williams, P. I., Cubison, M. J., DeCarlo, P. F., and Dunlea, E. J.: Exploring the vertical profile of atmospheric organic aerosol: comparing 17 aircraft field campaigns with a global model, Atmos. Chem. Phys., 11, 12673-12696, doi:10.5194/acp-11-12673-2011, 2011.

Hinkelman, L. M., Stackhouse, Paul W., J., Wielicki, B. A., Zhang, T., and Wilson, S. R.: Surface insolation trends from satellite and ground measurements: Comparisons and challenges, J. Geophys. Res., 114, D00D20, doi:10.1029/2008jd011004, 2009.

Hoff, R. M. and Christopher, S. A.: Remote sensing of particulate pollution from space: Have we reached the promised land?, J. Air Waste Manage., 59, 645-675, doi:10.3155/1047-3289.59.6.645, 2009.

Kahn, R. A., Garay, M. J., Nelson, D. L., Yau, K. K., Bull, M. A., Gaitley, B. J., Martonchik, J. V., and Levy, R. C.: Satellite-derived aerosol optical depth over dark water from MISR and MODIS: Comparisons with AERONET and implications for climatological studies, J. Geophys. Res., 112, D18205, doi:10.1029/2006jd008175, 2007.

Kahn, R. A., Nelson, D. L., Garay, M. J., Levy, R. C., Diner, D. J., Martonchik, J. V., Paradise, S. R., Hansen, E. G., and Remer, L. A.: MISR Aerosol product attributes and statistical comparisons with MODIS, IEEE T. Geosci. Remote, 47, 4095-4114, doi:10.1109/TGRS.2009.2023115, 2009.

Kahn, R. A., Gaitley, B. J., Garay, M. J., Diner, D. J., Eck, T. F., Smirnov, A., and Holben, B. N.: Multiangle Imaging SpectroRadiometer global aerosol product assessment by comparison with the Aerosol Robotic Network, J. Geophys. Res., 115, D23209, doi:10.1029/2010jd014601, 2010.

Kahn, R. A., Garay, M. J., Nelson, D. L., Levy, R. C., Bull, M. A., Diner, D. J., Martonchik, J. V., Hansen, E. G., Remer, L. A., and Tanré, D.: Response to "Toward unified satellite climatology of aerosol properties. 3. MODIS versus MISR versus AERONET”, J. Quant. Spectrosc. Ra., 112, 901-909, doi:10.1016/j.jqsrt.2010.11.001, 2011.

Koren, I., Remer, L. A., Kaufman, Y. J., Rudich, Y., and Martins, J. V.: On the twilight zone between clouds and aerosols, Geophys. Res. Lett., 34, L08805, doi:10.1029/2007g1029253, 2007.

Lee, S., Wang, Y., and Russell, A. G.: Assessment of secondary organic carbon in the Southeastern United States: A review, J. Air Waste Manage., 60, 1282-1292, doi:10.3155/10473289.60.11.1282, 2010.

Levy, R. C., Remer, L. A., Martins, J. V., Kaufman, Y. J., Plana-Fattori, A., Redemann, J., and Wenny, B.: Evaluation of the MODIS Aerosol Retrievals over Ocean and Land during CLAMS, J. Atmos. Sci., 62, 974-992, doi:10.1175/jas3391.1, 2005.

Levy, R. C., Remer, L. A., Mattoo, S., Vermote, E. F., and Kaufman, Y. J.: Second-generation operational algorithm: Retrieval of aerosol properties over land from inversion of Moderate Resolution Imaging Spectroradiometer spectral reflectance, J. Geophys. Res., 112, D13211, doi:10.1029/2006JD007811, 2007.

Levy, R. C., Remer, L. A., Kleidman, R. G., Mattoo, S., Ichoku, C., Kahn, R., and Eck, T. F.: Global evaluation of the Collection 5 MODIS dark-target aerosol products over land, Atmos. Chem. Phys., 10, 10399-10420, doi:10.5194/acp-10-10399-2010, 2010.

Liu, L. and Mishchenko, M. I.: Toward unified satellite climatology of aerosol properties: Direct comparisons of advanced level 
2 aerosol products, J. Quant. Spectrosc. Ra., 109, 2376-2385, doi:10.1016/j.jqsrt.2008.05.003, 2008.

Long, C. N., Dutton, E. G., Augustine, J. A., Wiscombe, W., Wild, M., McFarlane, S. A., and Flynn, C. J.: Significant decadal brightening of downwelling shortwave in the continental United States, J. Geophys. Res., 114, D00D06, doi:10.1029/2008jd011263, 2009.

Martonchik, J. V., Diner, D. J., Crean, K. A., and Bull, M. A.: Regional aerosol retrieval results from MISR, IEEE T. Geosci. Remote, 40, 1520-1531, 2002.

Martonchik, J. V., Kahn, R. A., and Diner, D. J.: Retrieval of aerosol properties over land using MISR observations, in: Satellite Aerosol Remote Sensing Over Land, edited by: Kokhanovsky, A. A. and de Leeuw, G., Springer, Berlin, 2009.

Menne, M., Williams, C., and Vose, R.: The U.S. Historical Climatology Network Monthly Temperature Data, Version 2, B. Am. Meterol. Soc., 90, 993-1007, doi:10.1175/2008BAMS2613.1, 2009

Mishchenko, M., Geogdzhayev, I., Rossow, W., Cairns, B., Carlson, B., Lacis, A., Liu, L., and Travis, L.: Long-term satellite record reveals likely recent aerosol trend, Science, 315, 1543, doi:10.1126/science.1136709, 2007.

Remer, L. A., Kleidman, R. G., Levy, R. C., Kaufman, Y. J., Tanré, D., Mattoo, S., Martins, J. V., Ichoku, C., Koren, I., Yu, H., and Holben, B. N.: Global aerosol climatology from the MODIS satellite sensors, J. Geophys. Res., 113, D14S07, doi:10.1029/2007jd009661, 2008.

Schwartz, S. E., Charlson, R. J., Kahn, R. A., Ogren, J. A., and Rodhe, H.: Why hasn't Earth warmed as much as expected?, J. Climate, 23, 2453-2464, doi:10.1175/2009JCLI3461.1, 2010.

Solomon, P. A., Baumann, K., Edgerton, E. S., Tanner, R., Eatough, D., Modey, W., Maring, H., Savoie, D., Natarajan, S., Meyer, M. B., and Norris, G.: Comparison of integrated samplers for mass and composition during the 1999 Atlanta Supersites project, J. Geophys. Res., 108, 8423, doi:10.1029/2001JD001218, 2003a.

Solomon, P. A., Chameides, W., Weber, R. J., Middlebrook, A., Kiang, C. S., Russell, A. G., Butler, A., Turpin, B., Mikel, D., Scheffe, R., Cowling, E., Edgerton, E., St. John, J., Jansen, J., McMurry, P., Hering, S., and Bahadori, T.: Overview of the 1999 Atlanta Supersite Project, J. Geophys. Res., 108, 8413, doi:10.1029/2001JD001458, 2003b.
Streets, D. G., Yan, F., Chin, M., Diehl, T., Mahowald, N., Schultz, M., Wild, M., Wu, Y., and Yu, C.: Anthropogenic and natural contributions to regional trends in aerosol optical depth, 1980-2006, J. Geophys. Res., 114, D00D18, doi:10.1029/2008jd011624, 2009.

Wang, J. and Martin, S. T.: Satellite characterization of urban aerosols: Importance of including hygroscopicity and mixing state in the retrieval algorithms, J. Geophys. Res., 112, D17203, doi:10.1029/2006JD008078, 2007.

Weber, R. J., Orsini, D, Bergin, M. H., Kiang, C. S., John, J. S., Carrico, C. M., Lee, Y. N., Dasgupta, P, Slanina, J., Turpin, B., Edgerton, E. S., Hering, S., Allen, G., Solomon, P. A., and Chameides, W.: Short-term temporal variation in $\mathrm{PM}_{2.5}$ mass and chemical composition during the Atlanta Supersite Experiment, 1999, J. Air Waste Manage., 53, 84-91, 2003.

Weber, R. J., Sullivan, A., Peltier, R., Russell, A., Yan, B., Zheng, M., de Gouw, J., Warneke, C., Brock, C., Holloway, J., Atlas, E., and Edgerton, E. S.: A study of secondary organic aerosol formation in the anthropogenic-influenced southeastern United States, J. Geophys. Res., 112, D13302, doi:10.1029/2007JD008408, 2007.

Wen, G., Marshak, A., Cahalan, R. F., Remer, L. A., and Kleidman, R. G.: 3-D aerosol-cloud radiative interaction observed in collocated MODIS and ASTER images of cumulus cloud fields, J Geophys. Res., 112, D13204, doi:10.1029/2006jd008267, 2007.

Wild, M., Trüssel, B., Ohmura, A., Long, C. N., König-Langlo, G., Dutton, E. G., and Tsvetkov, A.: Global dimming and brightening: An update beyond 2000, J. Geophys. Res., 114, D00D13, doi:10.1029/2008jd011382, 2009.

Zhang, H., Hoff, R., and Engel-Cox, J. A.: The relation between Moderate Resolution Imaging Spectroradiometer (MODIS) aerosol optical depth and $\mathrm{PM}_{2.5}$ over the United States: A geographical comparison by US Environmental Protection Agency regions, J. Air Waste Manage., 59, 1358-1369, doi:10.3155/1047-3289.59.11.1358, 2009.

Zhang, J., Reid, J. S., and Holben, B. N.: An analysis of potential cloud artifacts in MODIS over ocean aerosol optical thickness products, Geophys. Res. Lett., 32, 15803 , doi:10.1029/2005GL023254, 2005. 